\title{
A methodological approach of the current literature on microplastic contamination in terrestrial environments: Current knowledge and baseline considerations.
}

Dioses-Salinas, Diana Carolina, Pizarro-Ortega, Carlos Ivan y De-la-Torre, Gabriel Enrique.

Cita:

Dioses-Salinas, Diana Carolina, Pizarro-Ortega, Carlos Ivan y De-laTorre, Gabriel Enrique (2020). A methodological approach of the current literature on microplastic contamination in terrestrial environments: Current knowledge and baseline considerations. Science of The Total Environment, 730, 13916-4.

Dirección estable: https://www.aacademica.org/gabriel.e.delatorre/2 ARK: https://n2t.net/ark:/13683/podQ/utO

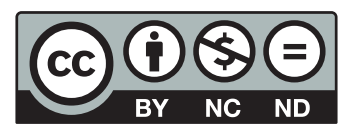


Review

\title{
A methodological approach of the current literature on microplastic contamination in terrestrial environments: Current knowledge and baseline considerations
}

\author{
Diana Carolina Dioses-Salinas *, Carlos Ivan Pizarro-Ortega, Gabriel Enrique De-la-Torre \\ Universidad San Ignacio de Loyola, Lima, Peru
}

\section{H I G H L I G H T S}

- MPs abundance in soil depend on the source, site characteristic and methods used.

- Reporting the MP types and chemical classification is mandatory.

- Heterogeneity of methods used in literature make results incomparable.

- Novel methods need to overcome important frontiers and challenges.

- Minimal standards along the extraction and identification procedure are suggested.

\section{G R A P H I C A L A B S T R A C T}

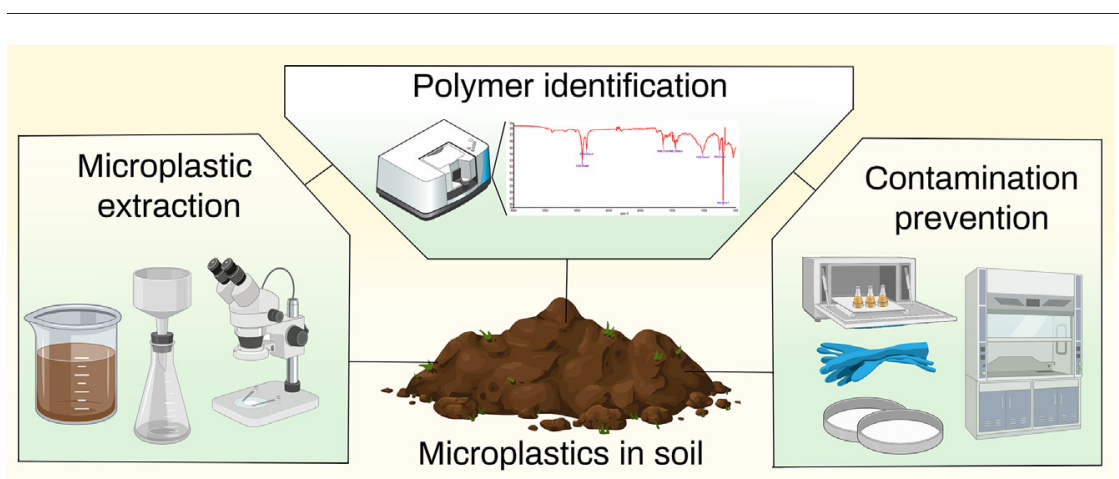

\section{A B S T R A C T}

Plastic pollution is one of the major challenges in the Anthropocene. A plastic waste sub-product, microplastics $(<5 \mathrm{~mm})$, has been regarded as contaminants of concern for its detrimental effects and widespread in the environment. Most studies assessing microplastics focused on marine environments, while terrestrial and soil systems have been overlooked. In this review, we analyzed the current knowledge regarding microplastic pollution in natural soil or agricultural ecosystems. We focused on reviewing the procedural steps for microplastic extraction and identification in detail. The heterogeneity of the methods applied, lack of standardized procedures and incompatible parameters reported, make the results incomparable among most studies. Several microplastic concentration units are needed to make studies comparable. Correctly determining and reporting microplastic morphotypes are key to understanding the sources of contamination. Minimal considerations and recommendations were stated for extraction, digestion, filtration, and polymer identification procedures. Baseline contamination prevention measures were identified as mandatory along the entire sampling, handling and identification procedures. Lastly, knowledge gaps were identified and discussed for further research.

C 2018 Published by Elsevier B.V.

\footnotetext{
* Corresponding author at: Universidad San Ignacio de Loyola, Faculty of Engineering, Av. la Fontana 501, La Molina, Lima, Peru.

E-mail address: diana.dioses@usil.pe (D.C. Dioses-Salinas).
} 


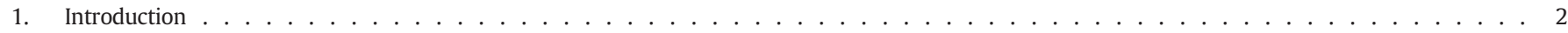

2. Literature review strategy . . . . . . . . . . . . . . . . . . . . . . . . . . . . . . . . . . . . .

3. Microplastic occurrence in soil environments . . . . . . . . . . . . . . . . . . . . . . . . . . . . . . . . . 2

4. Microplastic classification criteria . . . . . . . . . . . . . . . . . . . . . . . . . . . . . . . . 6

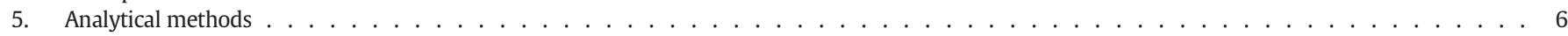

5.1. Microplastic extraction . . . . . . . . . . . . . . . . . . . . . . . . . . . . . . . 6

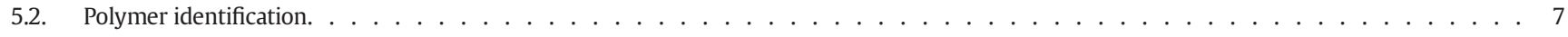

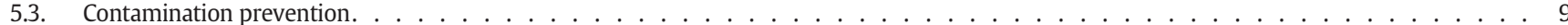

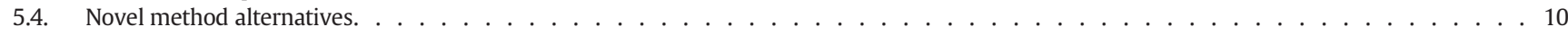

6. Knowledge gaps and recommendations . . . . . . . . . . . . . . . . . . . . . . . . . . . . . . . . . . . 11

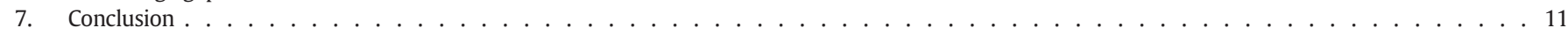

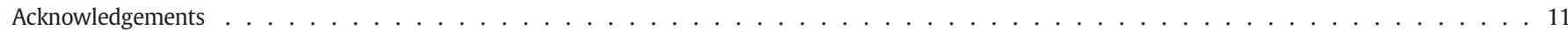

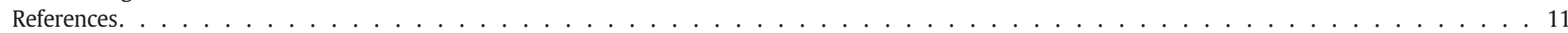

\section{Introduction}

Microplastics (MPs, plastic particles smaller than $5 \mathrm{~mm}$ ) are contaminants of growing concern among scientists and the public opinion (Barboza and Gimenez, 2015) as they are a ubiquitous pollutant in the marine and terrestrial environment (Wang et al., 2019; Andrady, 2011). Primary MPs are manufactured micro-sized, while secondary MPs derive from the breakdown of larger plastics due to photolytic, mechanical fragmentation and biological degradation (Cole et al., 2011; Browne et al., 2009). Importantly, MPs come from a wide range of sources, but are classified as terrestrial (e.g., clothing, single-use plastics or worn off tire rubber) or marine (e.g., fishing gear or buoys) (Cole et al., 2011) and are able to carry associated organic pollutants (PAHs, PCBs, OCP) and heavy metals (Camacho et al., 2019; Li et al., 2020a, 2020b; Y. Zhou et al., 2019).

MPs have been reported in marine ecosystems (e.g., AlvarezZeferino et al., 2020; De-la-Torre et al., 2020), freshwater bodies (e.g., Bordós et al., 2019), agricultural soils and terrestrial ecosystems (e.g., Corradini et al., 2019; Liu et al., 2018; Chen et al., 2019; Scheurer and Bigalke, 2018). Many organisms are subject to MP ingestion due to their small size and distribution in the environment (De-la-Torre, 2020). Although MPs have been widely investigated in marine ecosystems, terrestrial ecosystems and agroecosystems have been overlooked (Qi et al., 2020).

MPs reach agricultural and natural soil environments through land applications, including sewage sludging (Van den Berg et al., 2020), plastic mulching (Huang et al., 2020) and organic fertilizers (Weithmann et al., 2018); applying wastewater treatment plant discharge (Conley et al., 2019) and other irrigation methods using contaminated river water (Wong et al., 2020); tire wear (Sommer et al., 2018); or atmospheric deposition (Qi et al., 2020). Upon reaching terrestrial environments, MPs are expected to interact with soil biota. Detrimental effects and interaction with MPs have been researched in annelids (e.g., Chen et al., 2020; Huerta Lwanga et al., 2017), nematodes (e.g., Lei et al., 2018; Shang et al., 2020), arthropods (e.g., Wu et al., 2018), and soil microbiota (e.g., de Souza Machado et al., 2018). Fewer studies have focused on its implications for plants of commercial relevance (e.g., Bosker et al., 2019; Qi et al., 2018). Hence, MPs threaten the wellbeing of soil biota. For this reason, assessing the presence of MPs in soil environments is a global concern.

The characteristics of the soil ecosystems vary depending on many factors (e.g., soil texture, organic matter content), becoming a heterogeneous environmental matrix. A wide range of techniques and procedures has been developed for MP isolation and quantification from substrata, including density separation techniques, organic matter digestion, sieving or filtration, among others. However, no standard procedure or protocol has been established for assessing MPs in soil.

Consequently, this review will focus on: (1) The current knowledge on MP occurrence, sources and distribution in terrestrial ecosystems and (2) methods for MP extraction, identification and contamination prevention. Baseline considerations were identified and summarized along the MP assessment process. Knowledge gaps were discussed based on the available literature.

\section{Literature review strategy}

In March 2020, a literature review was carried out to retrieve articles on MPs in soil ecosystems from the Scopus (https://www.scopus.com/) database. Following Wang et al. (2020), the keywords used for the search were "microplastic" in conjunction with "soil" or "terrestrial". Publications were selected and retrieved only if they fell into one of two categories: Environmental or agricultural soil MP assessment, or development of novel analytical methods. Publications assessing sediments from water bodies were excluded. Review articles also applied if they were relevant to the matter of the present study. The reference list from the retrieved articles were also checked and retrieved when deemed necessary. A total of 27 papers were selected, 10 assessing MPs in natural, industrial or agricultural soil environments, 15 presenting novel analytical methods applied to soil samples and two that included both topics.

\section{Microplastic occurrence in soil environments}

Recent studies have reported MP contamination in areas adjacent or close to anthropogenic activities, principally in agricultural soils (B. Zhou et al., 2019; Chen et al., 2019; Corradini et al., 2019; Liu et al., 2018; Piehl et al., 2018; S. Zhang et al., 2018, 2020; Zhang and Liu, 2018, Y. Zhou et al., 2019), but also in soils of industrial areas (Fuller and Gautam, 2016), beaches (Álvarez-Hernández et al., 2019), vacant lands and woodlands in suburb areas of cities (Zhang and Liu, 2018) and flood plains close to populated areas (Scheurer and Bigalke, 2018). The result of these studies may suggest a ubiquitous presence of MPs in soil environments, regardless of the proximity or remoteness of human activity. However, significant differences were reported mainly in terms of abundance and chemical composition, even in soils of the same land use. Some similarities were found in MP morphological types and size composition. These results seem to be conditioned by the sources of MPs in the surrounding areas, hydrogeographic characteristics (e.g., topography, hydrography, and presence of ocean currents) and the limitations of the extraction and identification methods used (Álvarez-Hernández et al., 2019; B. Zhou et al., 2019; Piehl et al., 2018; Scheurer and Bigalke, 2018).

On non-agricultural soils (vacant lands, woodlands, forests, floodplains and beaches), concentrations of MPs varied greatly among studies. Studies that reported higher MPs concentrations sampled sites close to urban or industrial areas (Fuller and Gautam, 2016; Scheurer and Bigalke, 2018; Y. Zhou et al., 2019) or identified a key environmental factor facilitating the accumulation of MPs, such as ocean currents 
Table 1

Summary of the results reported by the selected studies.

\begin{tabular}{|c|c|c|c|c|c|c|c|c|c|c|}
\hline \multirow[t]{2}{*}{ Country } & \multirow{2}{*}{$\begin{array}{l}\text { Land } \\
\text { type }^{\mathrm{a}}\end{array}$} & \multirow{2}{*}{$\begin{array}{l}\text { Soil } \\
\text { taxonomy }\end{array}$} & \multirow{2}{*}{$\begin{array}{l}\text { Depth } \\
\text { sampling }^{\mathrm{c}}\end{array}$} & \multicolumn{6}{|l|}{ Microplastics } & \multirow[t]{2}{*}{ Reference } \\
\hline & & & & Abundance $^{\mathrm{d}}$ & Polymer $^{\mathrm{e}}$ & Morphology $^{\mathrm{f}}$ & Size $^{g}$ & Color $^{\text {h }}$ & Source $^{\mathrm{i}}$ & \\
\hline \multirow[t]{4}{*}{ China } & VL & - & $\mathrm{S}-5 \mathrm{~cm}$ & $\begin{array}{l}2.2 \times 10^{4} \text { to } \\
2 \times 10^{5} \mathrm{p} / \mathrm{kg}\end{array}$ & - & $\begin{array}{l}\text { FR-50.5\% } \\
\text { FB-10.4\% }\end{array}$ & - & - & - & \multirow[t]{4}{*}{$\begin{array}{l}\text { Y. Zhou et al. } \\
(2019)\end{array}$} \\
\hline & WO & - & $\mathrm{S}-5 \mathrm{~cm}$ & $\begin{array}{l}9.6 \times 10^{4} \text { to } \\
6.9 \times 10^{5} \mathrm{p} / \mathrm{kg}\end{array}$ & - & $\begin{array}{l}\text { FR-55.4\% } \\
\text { FB-12.1\% }\end{array}$ & - & - & wi, sw, in & \\
\hline & FA & - & $\mathrm{S}-5 \mathrm{~cm}$ & $\begin{array}{l}4.3 \times 10^{4} \text { to } \\
6.2 \times 10^{5} \mathrm{p} / \mathrm{kg}\end{array}$ & - & $\begin{array}{l}\text { FR-49.9\% } \\
\text { FB-20.8\% }\end{array}$ & - & - & wi, sw, mu & \\
\hline & AV & - & $\mathrm{S}-5 \mathrm{~cm}$ & $2.2 \times 10^{5} \mathrm{p} / \mathrm{kg}$ & $\begin{array}{l}\text { PE-36.1\%, } \\
\text { PA- } 17.3 \% \\
\text { PP- } 11.5 \%\end{array}$ & $\begin{array}{l}\text { FR-51.7\% } \\
\text { FB-15.2\% }\end{array}$ & $<50 \mu \mathrm{m}-46.1 \%$ & - & - & \\
\hline \multirow[t]{2}{*}{ Chile } & $\mathrm{FA}^{\mathrm{sw}}$ & $\mathrm{a}$ & $\mathrm{S}-\mathrm{V}$ & $\begin{array}{l}1.37 \text { to } \\
4.38 \mathrm{mg} / \mathrm{kg}\end{array}$ & - & FB-97\% & $<2 \mathrm{~mm}-80 \%$ of fibers & - & sw & \multirow[t]{2}{*}{$\begin{array}{l}\text { Corradini et al. } \\
\text { (2019) }\end{array}$} \\
\hline & $\mathrm{FA}^{\mathrm{nsw}}$ & - & $\mathrm{S}-\mathrm{V}$ & 1 to $3 \mathrm{p} / 5 \mathrm{~g}$ soil & - & - & - & - & at, sc & \\
\hline Germany & $\mathrm{FA}^{\mathrm{ca}}$ & $\begin{array}{l}\text { EN } \\
\text { VR }\end{array}$ & $\mathrm{S}-5 \mathrm{~cm}$ & $\begin{array}{l}0.34 \pm 0.36 \mathrm{p} / \mathrm{kg} \\
\text { DW } \\
158,100 \text { to } \\
292,400 \mathrm{p} / \mathrm{ha}\end{array}$ & $\begin{array}{l}\text { PE-62.5\% } \\
\text { PP- } 25.0 \% \\
\text { PS- } 12.5 \%\end{array}$ & $\begin{array}{l}\text { FR- } 43.75 \% \\
\text { FI- } 43.75 \% \\
\text { FB- } 12.5 \%\end{array}$ & $<5 \mathrm{~mm}-68.75 \%$ & $\begin{array}{l}\text { W-62.5\% } \\
\text { T-18.75\% } \\
\text { BU-12.50\% }\end{array}$ & $\begin{array}{l}\text { pwd, surface } \\
\text { creep }\end{array}$ & Piehl et al. (2018) \\
\hline \multirow[t]{2}{*}{ China } & FA & - & $\mathrm{S}-3 \mathrm{~cm}$ & $\begin{array}{l}78.00 \\
\pm 12.91 \text { items } / \mathrm{kg}\end{array}$ & $\begin{array}{l}\text { PP- } 50.51 \% \\
\text { PE-43.43\% } \\
\text { PES-6.06\% }\end{array}$ & $\begin{array}{l}\text { FB-53.33\% } \\
\text { FR-37.58\% } \\
\text { FI-6.67\%* }\end{array}$ & $<1 \mathrm{~mm}-48.79^{*}$ & $\begin{array}{l}\text { BA-39.39\% } \\
*\end{array}$ & Mu, pwd, sw & \multirow[t]{2}{*}{ Liu et al. (2018) } \\
\hline & FA & - & $\begin{array}{l}\mathrm{D}-3 \text { to } \\
6 \mathrm{~cm}\end{array}$ & $\begin{array}{l}62.50 \pm 12.97 \\
\text { items } / \mathrm{kg}\end{array}$ & & $\begin{array}{l}\text { FB-37.62\% } \\
\text { FI-33.76\% } \\
\text { FR-28.30\%* }\end{array}$ & $<1 \mathrm{~mm}-59.81 \% *$ & $\mathrm{~T}-46.30 \% *$ & $\begin{array}{l}\text { Soil } \\
\text { ploughed, } \\
\text { pwd, sw }\end{array}$ & \\
\hline China & FA & - & $\mathrm{S}-5 \mathrm{~cm}$ & $\begin{array}{l}2020 \text { items } / \mathrm{kg} \\
\text { dry weight }\end{array}$ & $\begin{array}{l}\text { PA-32.5\% } \\
\text { PP-28.8\% } \\
\text { PS-16.9\% }\end{array}$ & $\begin{array}{l}\text { MB-48\% } \\
\text { FB-37\% } \\
\text { FR-15\% }\end{array}$ & $\begin{array}{l}<0.2 \mathrm{~mm}-70 \% \\
0.5 \text { to } 1 \mathrm{~mm}-13 \% \\
0.2 \text { to } 0.5 \mathrm{~mm}-9 \%\end{array}$ & - & & Chen et al. (2019) \\
\hline China & FA & - & $\mathrm{S}-10 \mathrm{~cm}$ & 503.3 pieces $/ \mathrm{kg}$ & - & $\begin{array}{l}\text { FR-75\% to } \\
100 \%\end{array}$ & From 0.06 to $5 \mathrm{~mm}$ & - & $\begin{array}{l}\text { mu, pwd, } \\
\text { wi, co }\end{array}$ & $\begin{array}{l}\text { B. Zhou et al. } \\
\text { (2019) }\end{array}$ \\
\hline \multirow[t]{7}{*}{ China } & FA & $\mathrm{NI}$ & $\mathrm{S}-5 \mathrm{~cm}$ & $12,960 \mathrm{p} / \mathrm{kg}^{*}$ & - & $\begin{array}{l}\text { FB- } 11130 \text { to } \\
14,680 \mathrm{p} / \mathrm{kg} \\
\text { FR-230 to } \\
1060 \mathrm{p} / \mathrm{kg} \\
\text { FI-460 to } 520 \\
\mathrm{p} / \mathrm{kg}^{*}\end{array}$ & $\begin{array}{l}0.05 \text { to } 0.25 \mathrm{~mm}-11,170 \text { to } \\
13,430 \mathrm{p} / \mathrm{kg} \\
0.25 \text { to } 1.00 \mathrm{~mm}-1080 \text { to } \\
1490 \mathrm{p} / \mathrm{kg}\end{array}$ & - & sw, wi, mu & $\begin{array}{l}\text { Zhang and Liu } \\
(2018)\end{array}$ \\
\hline & FA & $\mathrm{NI}$ & $\begin{array}{l}\mathrm{D}-5 \text { to } \\
10 \mathrm{~cm}\end{array}$ & & - & $\begin{array}{l}\text { FB- } 9780 \text { to } \\
12,210 \mathrm{p} / \mathrm{kg} \\
\text { FI-410 to } 550 \\
\mathrm{p} / \mathrm{kg} \\
\text { FR-170 to } \\
500 \mathrm{p} / \mathrm{kg}^{*}\end{array}$ & $\begin{array}{l}0.05 \text { to } 0.25 \mathrm{~mm}-9560 \text { to } \\
10,900 \mathrm{p} / \mathrm{kg} \\
0.25 \text { to } 1.00 \mathrm{~mm}-800 \text { to } 1490 \\
\mathrm{p} / \mathrm{kg}\end{array}$ & - & sw, wi, mu & \\
\hline & FA & GY & $\mathrm{S}-5 \mathrm{~cm}$ & $26,070 \mathrm{p} / \mathrm{kg}^{*}$ & - & $\begin{array}{l}\text { FB-23000 to } \\
24,850 \mathrm{p} / \mathrm{kg} \\
\text { FR-650 to } \\
1360 \mathrm{p} / \mathrm{kg} \\
\text { FI-640 to } 650 \\
\mathrm{p} / \mathrm{kg}^{*}\end{array}$ & $\begin{array}{l}0.05 \text { to } 0.25 \mathrm{~mm}-20,530 \text { to } \\
22,320 \mathrm{p} / \mathrm{kg} \\
0.25 \text { to } 1.00 \mathrm{~mm}-2040 \text { to } \\
4080 \mathrm{p} / \mathrm{kg}\end{array}$ & - & sw, wi, mu & \\
\hline & FA & GY & $\begin{array}{l}\mathrm{D}-5 \text { to } \\
10 \mathrm{~cm}\end{array}$ & & - & $\begin{array}{l}\text { FB-24920 to } \\
26,940 \mathrm{p} / \mathrm{kg} \\
\text { FR-480 to } \\
1570 \mathrm{p} / \mathrm{kg} \\
\mathrm{FI}-570 \text { to } \\
1290 \mathrm{p} / \mathrm{kg}^{*}\end{array}$ & $\begin{array}{l}0.05 \text { to } 0.25 \mathrm{~mm}-20,290 \text { to } \\
25,960 \mathrm{p} / \mathrm{kg} \\
0.25 \text { to } 1.00 \mathrm{~mm}-2770 \text { to } \\
4060 \mathrm{p} / \mathrm{kg}\end{array}$ & - & sw, wi, mu & \\
\hline & $\mathrm{FB}$ & GY & $\mathrm{S}-5 \mathrm{~cm}$ & $14,360 \mathrm{p} / \mathrm{kg}^{*}$ & - & $\begin{array}{l}\text { FB-13990 } \\
\mathrm{p} / \mathrm{kg} \\
\text { FI-1140 p/kg } \\
\text { FR-810 p/kg* }\end{array}$ & $\begin{array}{l}0.05 \text { to } 0.25 \mathrm{~mm}-11,230 \mathrm{p} / \mathrm{kg} \\
0.25 \text { to } 1.00 \mathrm{~mm}-3370 \mathrm{p} / \mathrm{kg}\end{array}$ & - & & \\
\hline & FB & GY & $\begin{array}{l}\mathrm{D}-5 \text { to } \\
10 \mathrm{~cm}\end{array}$ & & - & $\begin{array}{l}\text { FB-13040 } \\
\mathrm{p} / \mathrm{kg} \\
\text { FI-780 p/kg } \\
\text { FR-550 p/kg* }\end{array}$ & $\begin{array}{l}0.05 \text { to } 0.25 \mathrm{~mm}-9230 \mathrm{p} / \mathrm{kg} \\
0.25 \text { to } 1.00 \mathrm{~mm}-2580 \mathrm{p} / \mathrm{kg}\end{array}$ & - & & \\
\hline & AV & - & - & $18,760 \mathrm{p} / \mathrm{kg}$ & - & $\begin{array}{l}\text { FB-92.0\% } \\
\text { FR-4.0\% } \\
\text { FI-3.7\% }\end{array}$ & $\begin{array}{l}1.00 \text { to } 0.05 \mathrm{~mm}-95 \% \\
0.05 \text { to } 0.025-82 \%\end{array}$ & & & \\
\hline Switzerland & $\mathrm{FP}^{\mathrm{nr}}$ & & $\mathrm{S}-5 \mathrm{~cm}$ & $5 \mathrm{mg} / \mathrm{kg}$ & PE-88\% & - & $<1.00 \mathrm{~mm}-85 \%$ & - & $\begin{array}{l}\text { At, river } \\
\text { water }\end{array}$ & $\begin{array}{l}\text { Scheurer and } \\
\text { Bigalke (2018) }\end{array}$ \\
\hline \multirow[t]{2}{*}{ Spain } & $\mathrm{BE}^{\mathrm{pc}}$ & - & $\mathrm{S}-5 \mathrm{~cm}$ & $\begin{array}{l}45.1 \text { items } / \mathrm{m}^{2} \\
1.2 \mathrm{~g} / \mathrm{m}^{2} \\
0.025 \mathrm{~g} / \mathrm{L}\end{array}$ & $\begin{array}{l}\text { PE-69\% } \\
\text { PP-18\% } \\
\text { PS-4\% }\end{array}$ & $\begin{array}{l}\text { FR-80\% } \\
\text { FB-7\% } \\
\text { FO-7\% }\end{array}$ & & - & - & $\begin{array}{l}\text { Álvarez-Hernández } \\
\text { et al. (2019) }\end{array}$ \\
\hline & $\mathrm{BE}^{\mathrm{npc}}$ & - & $\mathrm{S}-5 \mathrm{~cm}$ & $\begin{array}{l}2971.5 \text { items } / \mathrm{m}^{2} \\
99 \mathrm{~g} / \mathrm{m}^{2} \\
2.0 \mathrm{~g} / \mathrm{L}\end{array}$ & & $\begin{array}{l}\text { FR-87\% } \\
\text { PL-9\% } \\
\text { FI-2\% }\end{array}$ & $\begin{array}{l}4 \text { to } 5 \mathrm{~mm}-40.1 \%, 2 \text { to } 4 \mathrm{~mm} \\
\text { - } 45.7,1 \text { to } 2 \mathrm{~mm}-14.2 \%\end{array}$ & - & $\begin{array}{l}\text { Canary } \\
\text { current }\end{array}$ & \\
\hline Australia & - & - & - & - & PVC - 80\% & - & - & - & in & $\begin{array}{l}\text { Fuller and Gautam } \\
\text { (2016) }\end{array}$ \\
\hline China & FA & $\mathrm{MO}, \mathrm{b}$ & $\mathrm{S}-20 \mathrm{~cm}$ & 12.6 & PE-100\% & - & $>100 \mu \mathrm{m}-8400 \mathrm{~N} / \mathrm{kg}$ & - & $\mathrm{mu}$ & S. Zhang et al. \\
\hline
\end{tabular}


Table 1 (continued)

\begin{tabular}{|c|c|c|c|c|c|c|c|c|c|c|}
\hline \multirow[t]{2}{*}{ Country } & \multirow{2}{*}{$\begin{array}{l}\text { Land } \\
\text { type }^{\mathrm{a}}\end{array}$} & \multirow{2}{*}{$\begin{array}{l}\text { Soil } \\
\text { taxonomy }\end{array}$} & \multirow{2}{*}{$\begin{array}{l}\text { Depth } \\
\text { sampling }\end{array}$} & \multicolumn{6}{|l|}{ Microplastics } & \multirow[t]{2}{*}{ Reference } \\
\hline & & & & Abundance $^{\mathrm{d}}$ & Polymer $^{\mathrm{e}}$ & Morphology ${ }^{f}$ & Size $^{g}$ & Color $^{\text {h }}$ & Source $^{\mathrm{i}}$ & \\
\hline & & & & $\begin{array}{l} \pm 52.8 \mathrm{~mm}^{2} / \mathrm{kg} \\
0.27 \\
\pm 1.31 \mathrm{mg} / \mathrm{kg}\end{array}$ & & & 50 to $100 \mu \mathrm{m}-600 \mathrm{~N} / \mathrm{kg}$ & & & $(2020)$ \\
\hline & FA & MO, b & $\mathrm{S}-20 \mathrm{~cm}$ & $\begin{array}{l}0.40 \\
\pm 0.40 \mathrm{~mm}^{2} / \mathrm{kg} \\
0.002 \\
\pm 0.002 \mathrm{mg} / \mathrm{kg}\end{array}$ & PE-100\% & - & $\begin{array}{l}>100 \mu \mathrm{m}-400 \mathrm{~N} / \mathrm{kg} \\
50 \text { to } 100 \mu \mathrm{m}-400 \mathrm{~N} / \mathrm{kg}\end{array}$ & - & $\mathrm{mu}$ & \\
\hline & & FA & MO, b & D-20 to $30 \mathrm{~cm}$ & 5.20 & & $\begin{array}{l} \pm 10.41 \mathrm{~mm}^{2} / \mathrm{kg} \\
0.20 \pm 0.40 \mathrm{mg} / \mathrm{kg}\end{array}$ & PE-100\% & - & \\
\hline & $\begin{array}{l}>10- \\
0 \mu \mathrm{m}\end{array}$ & $\begin{array}{l}1400 \mathrm{~N} / \mathrm{kg} \\
50 \text { to }\end{array}$ & - & $\mathrm{mu}$ & & & & & & \\
\hline & - & $\begin{array}{l}100 \mu \mathrm{m}- \\
200 \mathrm{~N} / \mathrm{kg}\end{array}$ & & & & & & & & \\
\hline & & FA & MO, b & $\mathrm{S}-20 \mathrm{~cm}$ & 2.27 & & $\begin{array}{l} \pm 3.93 \mathrm{~mm}^{2} / \mathrm{kg} \\
0.012 \pm 0.021 \mathrm{mg} / \mathrm{kg}\end{array}$ & PE-100\% & - & \\
\hline & $\begin{array}{l}>10- \\
0 \mu \mathrm{m} \\
-\end{array}$ & $400 \mathrm{~N} / \mathrm{kg}$ & - & $\mathrm{mu}$ & & & & & & \\
\hline & FA & MO, b & $\mathrm{S}-20 \mathrm{~cm}$ & $\begin{array}{l}1.07 \\
\pm 1.85 \mathrm{~mm}^{2} / \mathrm{kg} \\
0.004 \\
\pm 0.008 \mathrm{mg} / \mathrm{kg}\end{array}$ & PE-100\% & - & $>100 \mu \mathrm{m}-200 \mathrm{~N} / \mathrm{kg}$ & - & $\mathrm{mu}$ & \\
\hline \multirow[t]{6}{*}{ China } & FA & - & $\mathrm{S}-10 \mathrm{~cm}$ & $\begin{array}{l}40 \pm 126 \mathrm{~N} / \mathrm{kg} \\
0.008 \\
\pm 0.025 \mathrm{~g} / \mathrm{kg}\end{array}$ & - & - & $>100 \mu \mathrm{m}-40 \mathrm{~N} / \mathrm{kg}$ & & $\mathrm{mu}$ & $\begin{array}{l}\text { S. Zhang et al. } \\
(2018)\end{array}$ \\
\hline & FA & - & $\begin{array}{l}\mathrm{D}-10 \text { to } \\
30 \mathrm{~cm}\end{array}$ & $\begin{array}{l}100 \pm 141 \mathrm{~N} / \mathrm{kg} \\
0.368 \\
\pm 0.740 \mathrm{~g} / \mathrm{kg}\end{array}$ & - & - & $>100 \mu \mathrm{m}-100 \mathrm{~N} / \mathrm{kg}$ & - & $\mathrm{mu}$ & \\
\hline & $\mathrm{FF}$ & - & $\mathrm{S}-10 \mathrm{~cm}$ & $\begin{array}{l}320 \pm 329 \mathrm{~N} / \mathrm{kg} \\
0.540 \\
\pm 0.603 \mathrm{~g} / \mathrm{kg}\end{array}$ & - & - & $\begin{array}{l}>100 \mu \mathrm{m}-280 \mathrm{~N} / \mathrm{kg} \\
50 \text { to } 100 \mu \mathrm{m}-40 \mathrm{~N} / \mathrm{kg}\end{array}$ & - & $\mathrm{mu}$ & \\
\hline & $\mathrm{FF}$ & - & $\begin{array}{l}\text { D-10 to } \\
30 \mathrm{~cm}\end{array}$ & $\begin{array}{l}120 \pm 169 \mathrm{~N} / \mathrm{kg} \\
0.460 \\
\pm 0.735 \mathrm{~g} / \mathrm{kg}\end{array}$ & - & - & $\begin{array}{l}>100 \mu \mathrm{m}-100 \mathrm{~N} / \mathrm{kg} \\
50 \text { to } 100 \mu \mathrm{m}-20 \mathrm{~N} / \mathrm{kg}\end{array}$ & - & $\mathrm{mu}$ & \\
\hline & $\mathrm{GH}$ & - & $\mathrm{S}-10 \mathrm{~cm}$ & $\begin{array}{l}100 \pm 254 \mathrm{~N} / \mathrm{kg} \\
0.130 \\
\pm 0.307 \mathrm{~g} / \mathrm{kg}\end{array}$ & - & - & $\begin{array}{l}>100 \mu \mathrm{m}-80 \mathrm{~N} / \mathrm{kg} \\
50 \text { to } 100 \mu \mathrm{m}-20 \mathrm{~N} / \mathrm{kg}\end{array}$ & - & $\mathrm{mu}$ & \\
\hline & $\mathrm{GH}$ & - & $\begin{array}{l}\text { D-10 to } \\
30 \mathrm{~cm}\end{array}$ & $\begin{array}{l}80 \pm 193 \mathrm{~N} / \mathrm{kg} \\
0.024 \\
\pm 0.051 \mathrm{~g} / \mathrm{kg}\end{array}$ & - & - & $\begin{array}{l}>100 \mu \mathrm{m}-40 \mathrm{~N} / \mathrm{kg} \\
<50 \mu \mathrm{m}-40 \mathrm{~N} / \mathrm{kg}\end{array}$ & - & $\mathrm{mu}$ & \\
\hline
\end{tabular}

${ }^{a}$ VL (vacant land), WO (woodland), FA (farmland), AV (average), FB (forest buffer zone), FP (floodplain), BE (beach), FF (fruit field), GH (green house) ${ }^{\text {sw }}$ (sludge application), ${ }^{\text {nsw }}$ (no sludge application), ${ }^{\mathrm{ca}}$ (conventional agriculture), ${ }^{\mathrm{nr}}$ (national reserves), ${ }^{\mathrm{pc}}$ (periodic cleaning), ${ }^{\mathrm{npc}}$ (no periodic cleaning).

b a (Texture: loam and sandy loam), EN (entisol), VR (vertisol), NI (Nitisol), GY (Gleysol), MO (Mollisol), b (Texture: silty clay-loam).

c S (surface soil), D (deep soil).

d *(Account for micro- and mesoplastics).

e PE (polyethylene), PA (polyamide), PP (polypropylene), PS (polystyrene), PVC (polyvinyl chloride), PES (polyester).

${ }^{f}$ FR (fragments), FB (fibers), FI (films), MB (microbeads), FO (foams), PL (pellets), *(Results could not be separated from bigger plastics).

* (Results could not be separated from bigger plastics).

h W (white), T (transparent), BA (black), BU (blue), *(Results could not be separated from bigger plastics).

${ }^{\mathrm{i}}$ wi (wastewater irrigation), sw (sewage sludge application), in (industries), mu (mulching), at (aeolian transport), sc (sampling contamination), pwd (plastic waste degradation), co (compost application). 
(Álvarez-Hernández et al., 2019). MPs were also detected in remote areas such as high mountains in national reserves (Scheurer and Bigalke, 2018). The presence of MPs in such remote areas highlights the relevance of aeolian transport, transport through river water and other mechanisms that may exist.

In the case of agricultural soils (farmlands, fruit fields, green houses) some agricultural practices such as: sewage sludge application, mulching, greenhouse covering, compost application, use of organic fertilizers from biowaste fermentation and wastewater irrigation have been identified as possible sources of contamination of MPs in soils (Wang et al., 2020; B. Zhang et al., 2020). As seen on Table 1, many of the studies consulted also identified those factors as possible sources of MPs on their study sites. Moreover, by comparing the results presented by Piehl et al. (2018) and Y. Zhou et al. (2019a), the relevance of these factors is further understood. Piehl et al. (2018) surveyed a site $1.5 \mathrm{~km}$ away from an inhabited area, no agricultural plastic was used for cultivation and inputs via runoff were unlikely. The soil samples taken from this area presented one of the lowest concentrations of MPs $(0.34 \pm 0.36 \mathrm{MP}$ particles per kilogram) among the studies consulted. In contrast, Y. Zhou et al. (2019) surveyed a suburb area of a city in China where mulching, wastewater irrigation and sewage sludge application may have been applied to the vegetable plots, reporting average concentrations ranging from $4.3 \times 10^{4}$ to $6.2 \times 10^{5}$ particles $/ \mathrm{kg}$.

Assessment of surface and deep soil samples in agricultural soils were carried out by few authors. Results varied greatly among studies and even among samples on the same study. Some factors identified that may influence on the vertical distribution of MPs are: runoff, soil erosion, tillage practices, bioturbation by plant roots and animal transportation (Liu et al., 2018; S. Zhang et al., 2018, 2020; Zhang and Liu, 2018; Li et al., 2020a, 2020b). The abovementioned factors are classified by Li et al. (2020a, 2020b) as external factors that usually have a limited influence on the vertical transport of MPs, concentrated mainly on the surface. In contrast, other factors such as leaching can vertically transport MPs deeper (Li et al., 2020a, 2020b).

In terms of chemical composition in non-agricultural soils, polyethylene $(\mathrm{PE})$ is the most common polymer identified among the studies consulted (Álvarez-Hernández et al., 2019; Scheurer and Bigalke, 2018; Y. Zhou et al., 2019). In the case of agricultural soils, the most common polymers identified were PE, polyamide (PA) and polypropylene (PP) (Chen et al., 2019; Corradini et al., 2019; Liu et al., 2018; Piehl et al., 2018), reaching maximum average proportions of $62.5 \%, 32.5 \%$ and $50.51 \%$ respectively, among the studies consulted.

On the morphological aspect in non-agricultural soils, fragments were dominant in most of the study sites surveyed, followed by fibers. In agricultural soils, fibers were the most abundant morphological type of MPs or second most abundant (Chen et al., 2019; Corradini et al., 2019; Liu et al., 2018; Piehl et al., 2018; Y. Zhou et al., 2019). However, fiber prevalence was unlikely when farmlands received conventional agricultural treatment and were not subject to MP-containing fertilizers or agricultural plastic applications, in which case the most common MP morphologies were fragments and films (Piehl et al., 2018). B. Zhou et al. (2019) suggested that the presence of films, fragments and fibers are characteristic of farmlands. This seemed to be in accordance with the results of most of the studies consulted. Nevertheless, the sources of MPs (Fig. 1) may influence the morphological composition of MPs. For example, microbeads were the dominant MP found in farmlands located in the suburb of Wuhan city, China, probably due to the usage of personal care products by the urban population nearby (Chen et al., 2019).

Regarding size, Zhang and Liu (2018) reported an inverse relationship between concentration and size plastic particles finding higher concentrations of smaller MPs. Other studies in farmlands and nonfarmlands soils have reported the same behavior (Chen et al., 2019; Corradini et al., 2019; Liu et al., 2018; Scheurer and Bigalke, 2018; Y. Zhou et al., 2019). For example, Y. Zhou et al. (2019) reported that $>100 \mu \mathrm{m}$ and $>50 \mu \mathrm{m}$ MPs represented $81.3 \%$ and $46.1 \%$ respectively. In floodplain soils from Switzerland, 85\% of the MPs identified were classified in the small size range $(125-500 \mu \mathrm{m})$ (Scheurer and Bigalke, 2018).

The high variability of MP concentration may be due to human activity within reach and the characteristics of the surrounding environment. While some general similarities have been found in terms of morphological and size composition in the studies consulted, it is premature to suggest that this may be applied to all soils in general. Further investigations are needed and considerations must be taken in regard to the limitations of the methods of identification and extraction that may have biased the results by overlooking, altering MPs on the sample or reducing the extraction efficiency (Piehl et al., 2018; Scheurer and Bigalke, 2018; Y. Zhou et al., 2019). Moreover, MP abundance units must be standardized. We suggest expressing abundance results in both $\mathrm{MP} / \mathrm{kg}$ and $\mathrm{MP} / \mathrm{m}^{2}$ as a minimum requirement.

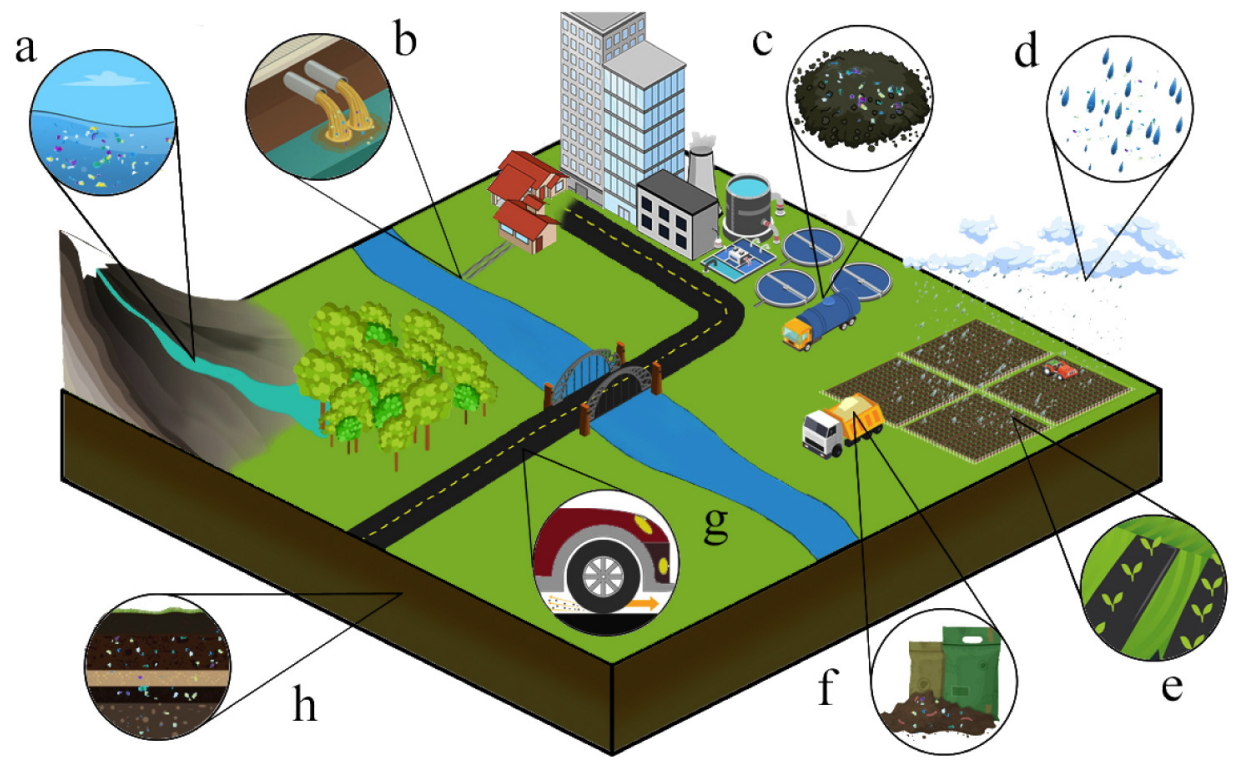

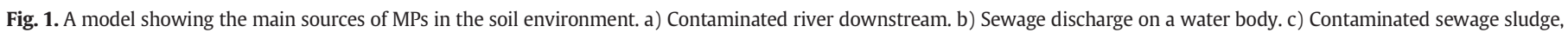
d) atmospheric deposition. e) Plastic mulching. f) Contaminated organic fertilizers. g) Tire rubber wear. h) Vertical distribution of MPs. 


\section{Microplastic classification criteria}

As for now, no methodology for classifying MPs by morphological shape has been established, thus different classification protocols have been used by different researchers (Wu et al., 2017). Correctly assigning a shape or morphological type to the observed MPs could provide hints on their origin (primary or secondary) and source. For example, fibers originate from fabrics and ropes; resin pellets and spheres (or microbeads) are engineered with those characteristics; films and sheets come from packaging and plastics bags; and foams degrade from shockabsorbing packing materials (Shim et al., 2018).

Reporting the abundance of specific morphological types or shapes is necessary as MPs of the same polymer type could come from different sources. In terrestrial agroecosystems, morphological types influence the distribution of MPs across the soil profile (Liu et al., 2018; Zhang and Liu, 2018). Other articles have classified their findings based on the material consistency of the MPs: hard and soft plastics (e.g., Garcia et al., 2020; Lima et al., 2015; Silva-Cavalcanti et al., 2017). However, this classification may not be the most appropriate to understand the origin and source of the MPs.

Wu et al. (2017) indicated six MP types typically assessed: Sheet, film, line/fiber, fragment, pellet/granule and foam. We suggest a more detailed classification, including microbeads (or spheres) and those indicated by Wu et al. (2017) but separating lines and fibers into two different categories, as fibers are most likely to shed from clothing, ropes or fabric and lines derive from finishing lines, two completely different sources.

Reporting the size of MPs is necessary to understand their bioavailability to certain organisms. For example, the smallest particles are most likely retained in earthworms and may be transferred along the terrestrial food chain (Huerta Lwanga et al., 2016). MP size is commonly categorized in length ranges that are variable depending on the isolated MPs. Galgani et al. (2013) considers two divisions: small MPs ( $<1 \mathrm{~mm})$ and large MPs (1-5 mm). For reporting MP sizes, however, we recommend to further divide size range categories (e.g., 100-500 $\mu \mathrm{m}$, 1-2 mm, 2-3 mm) to better understand the relation between MP abundance and size (e.g., Zhou et al., 2019).

The polymer type of MPs is commonly identified using chemicalanalytical methods. By further analyzing the suspected plastic particles, researchers can understand their origin and source and avoid false positives during visual identification. Although some key physical characteristics have been established to determine whether a suspected particle is a synthetic polymer or something else (Desforges et al., 2014), the results may be subject to bias by the observer. In some studies, visual sorting was effective enough to match $>90 \%$ of the visually identified MPs when compared to the polymer analysis (Ory et al., 2017). Moreover, according to Lenz et al. (2015), visually identified MPs smaller than $100 \mu \mathrm{m}$ presented significantly lower match percentages with confirmed MPs by Raman spectroscopy, suggesting that polymer identification is required for particles smaller than that. Still, we suggest polymer identification techniques as mandatory for particles smaller than $1 \mathrm{~mm}$ to assure the accuracy of the results.

\section{Analytical methods}

\subsection{Microplastic extraction}

Extraction procedures allow MP isolation from the soil matrix. Different techniques have been developed to eliminate inconveniences that may surge due to the heterogeneity of the soil matrix. For example, soil aggregates reduce the efficiency of extraction by absorbing or embedding MPs (Zhang and Liu, 2018). The presence of organic matter in the soil can also reduce the effectiveness of the extraction, as it cannot be properly separated by density solutions (Scheurer and Bigalke, 2018). Furthermore, the presence of carbonates can impede the efficient removal of organic matter (Corradini et al., 2019). A general description of the techniques is presented in Table 2.

Sieving allows to separate MPs from the soil matrix into granulometric fractions. It is a step commonly used as a pretreatment to remove particles larger than $5 \mathrm{~mm}$ (e.g., Corradini et al., 2019; Zhang and Liu, 2018). In some studies, sieving was performed in the field in order to recover MPs of a specific size (e.g., Álvarez-Hernández et al., 2019). This practice is recommended when plastic particles are visible to the naked eye, mostly exceeding $5 \mathrm{~mm}$ (mesoplastics). As soil is likely to be moist due to many factors, we suggest oven drying soil samples prior.

Density separation is a commonly used step (Corradini et al., 2019; Liu et al., 2018; Chen et al., 2019; B. Zhou et al., 2019; Y. Zhou et al., 2019). Effective extraction using a floatation technique depends on the sample mass, mixing method and sample:volume (floatation solution) ratio (Han et al., 2019). Flotation with high-density solutions, such as NaI $\left(1.8 \mathrm{~g} / \mathrm{cm}^{3}\right)$, allows a better MP separation than other solutions, like $\mathrm{NaCl}\left(1.2 \mathrm{~g} / \mathrm{cm}^{3}\right)$ or distilled water (Hurley et al., 2018). Liu et al. (2019) reported that $\mathrm{NaBr}$ is the best alternative compared to $\mathrm{CaCl}_{2}$ and $\mathrm{NaCl}$. The density of the floating solution must be verified in order to know what possible polymer types are likely to be missed. We suggest NaI as the best alternative for a high MP recovery rate and $\mathrm{NaCl}$ as the minimum requirement. It should be noted that $\mathrm{NaI}$ is an expensive and relatively toxic reagent to biota (Van Cauwenberghe et al., 2015). For this reason, cost-efficient, handling and disposal considerations must be taken into account when opting for NaI.

Digestion is a technique widely used for the elimination of organic matter in the samples. However, depending on the reagent used and incubation temperature, it can cause total or partial degeneration of some MPs. For instance, Hurley et al. (2018) performed digestion with $\mathrm{NaOH}$ $(10 \mathrm{M})$ at $70{ }^{\circ} \mathrm{C}$, and observed high degeneration in polyethylene terephthalate (PET) and polycarbonate (PC) MPs, while $\mathrm{KOH} \mathrm{(10 \% )} \mathrm{at}$ $60{ }^{\circ} \mathrm{C}$ mildly degraded polystyrene (PS) and PC MPs. Moreover, Desforges et al. (2015) reported that nylon, PET and biopolymer MPs were be degraded by $\mathrm{HNO}_{3}$. Some studies using $\mathrm{HNO}_{3}$ for tissue digestion indicated that their results are conservative estimates due to the possible loss of certain MPs (e.g., Md Amin et al., 2020; Sun et al., 2019). We recommend avoiding the use of $\mathrm{HNO}_{3}$ and $\mathrm{NaOH}$ as digesting agents.

Filtration permits the separation of MPs from the floating solution supernatant (Chen et al., 2019; Liu et al., 2018). This is most of the time the last step prior to visual sorting or polymer identification. Filter pore size selection is similar to a detection limit, as MPs smaller than that are expected to be lost. Talvitie et al. (2017) advises that an ideal porosity size be between $10 \mu \mathrm{m}$ and $20 \mu \mathrm{m}$. Selection of the smallest pore size is optimal for a larger size range of MP recovery. However, small porosity could be prone to a slow filtration process or in some cases becoming stuck.

The review of the 12 retrieved articles regarding the extraction methods revealed significant variability in the methodologies used. The time of sedimentation in many cases is not reported (Corradini et al., 2019; Piehl et al., 2018; Y. Zhou et al., 2019). While some studies indicated repeated extractions in the density separation method to increase the MP collection (Corradini et al., 2019; Y. Zhou et al., 2019), in most studies is not included or not mentioned (Zhang and Liu, 2018; B. Zhou et al., 2019; Chen et al., 2019). Similarly, most studies used different porosity sizes varying from $5 \mu \mathrm{m}$ to $1 \mathrm{~mm}$. Likewise, $40 \%$ of the studies consulted used $\mathrm{H}_{2} \mathrm{O}_{2}$ reagent for digestion, while only $10 \%$ used $\mathrm{KOH}$ (Y. Zhou et al., 2019) and $\mathrm{HNO}_{3}$ (Scheurer and Bigalke, 2018). There was only one study that did not use the methods mentioned above, but implemented a pressurized fluid extraction (PFE) technique (Fuller and Gautam, 2016). 
Table 2

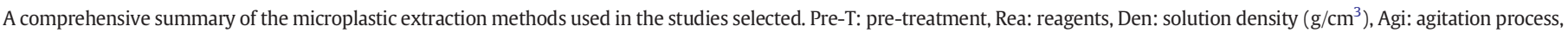
Tim: time, Con: concentration, Tem: temperature, Pos-T: post-treatment, Mat: filter material, Por: Pore size.

\begin{tabular}{|c|c|c|c|c|c|c|c|c|c|c|c|c|c|c|c|}
\hline \multirow{2}{*}{$\begin{array}{l}\text { General } \\
\text { method }^{\mathrm{a}}\end{array}$} & \multicolumn{5}{|c|}{ Density separation } & \multicolumn{6}{|c|}{ Digestion } & \multicolumn{3}{|c|}{ Filtration } & \multirow[t]{2}{*}{ Reference } \\
\hline & Pre- $T^{b}$ & $\operatorname{Rea}^{\mathrm{c}}$ & Den & $\mathrm{Agi}^{\mathrm{d}}$ & Tim & Pre-T & Rea & Con & Tem & Tim & Pos- $^{e}$ & $\mathrm{Mat}^{\mathrm{f}}$ & Por & Pos-T & \\
\hline OD, DS & Centri & $\begin{array}{l}\mathrm{NaCl}, \\
\mathrm{ZnCl}_{2}\end{array}$ & $\begin{array}{l}1.19 \\
(\mathrm{NaCl}), \\
1.55 \\
\left(\mathrm{ZnCl}_{2}\right)\end{array}$ & Centri & - & $\begin{array}{l}\text { Sie, } \mathrm{D} \\
\left(65{ }^{\circ} \mathrm{C}\right)\end{array}$ & $\begin{array}{l}\mathrm{KOH}: \mathrm{NaClO} \\
(1: 1) \text { Solution }\end{array}$ & $30 \%$ & $50{ }^{\circ} \mathrm{C}$ & $48 \mathrm{~h}$ & - & - & - & - & $\begin{array}{l}\text { Y. Zhou et al. } \\
(2019)\end{array}$ \\
\hline DS & $\begin{array}{l}\mathrm{D} \\
\left(40{ }^{\circ} \mathrm{C}\right) \\
\text { Sie }\end{array}$ & $\begin{array}{l}\mathrm{Dw}, \\
\mathrm{NaCl} \text {, } \\
\mathrm{ZnCl}_{2}\end{array}$ & $\begin{array}{l}1.2 \\
(\mathrm{NaCl}), \\
1.55 \\
\left(\mathrm{ZnCl}_{2}\right)\end{array}$ & Centri & - & - & - & - & - & - & - & - & $8 \mu \mathrm{m}$ & - & $\begin{array}{l}\text { Corradini et al. } \\
\text { (2019) }\end{array}$ \\
\hline $\mathrm{OD}, \mathrm{SI}$ & - & - & - & - & - & - & $\mathrm{H}_{2} \mathrm{O}_{2}$ & - & - & - & - & - & - & - & Piehl et al. (2018) \\
\hline DS, OD & $\begin{array}{l}\mathrm{D} \\
\left(70{ }^{\circ} \mathrm{C},\right. \\
24 \mathrm{~h})\end{array}$ & $\mathrm{NaCl}$ & 1.19 & $\begin{array}{l}\text { Ultra, } \\
\text { Man }\end{array}$ & $24 \mathrm{~h}$ & - & $\mathrm{H}_{2} \mathrm{O}_{2}$ & $30 \%$ & $50{ }^{\circ} \mathrm{C}$ & $72 \mathrm{~h}$ & - & Nyl & $20 \mu \mathrm{m}$ & - & Liu et al. (2018) \\
\hline DS & $\mathrm{AD}$ & $\mathrm{ZnCl}_{2}$ & 1.5 & Man & $24 \mathrm{~h}$ & - & - & - & - & - & - & GF & $45 \mu \mathrm{m}$ & - & Chen et al. (2019) \\
\hline DS, OD & $\begin{array}{l}\mathrm{AD}, \text { sie, } \\
\left(\mathrm{NaPO}_{3}\right) \\
6\end{array}$ & $\begin{array}{l}\mathrm{NaCl}, \\
\mathrm{NaI}\end{array}$ & $\begin{array}{l}1.2 \\
(\mathrm{NaCl}), \\
1.6 \\
(\mathrm{NaI})\end{array}$ & - & $\begin{array}{l}48 \mathrm{~h} \\
(\mathrm{NaI})\end{array}$ & - & $\mathrm{H}_{2} \mathrm{O}_{2}$ & $30 \%$ & $70{ }^{\circ} \mathrm{C}$ & $72 \mathrm{~h}$ & - & $\begin{array}{l}\text { Cel-Nit } \\
\text { (DS), } \\
\text { GF } \\
\text { (OD) }\end{array}$ & $\begin{array}{l}5 \mu \mathrm{m} \\
(\mathrm{DS}), \\
20 \mu \mathrm{m} \\
(\mathrm{OD})\end{array}$ & & $\begin{array}{l}\text { B. Zhou et al. } \\
\text { (2019) }\end{array}$ \\
\hline OD, DS & - & $\mathrm{NaI}$ & 1.8 & Centri & - & AD, Sie & $\mathrm{H}_{2} \mathrm{O}_{2}+\mathrm{FeSO}_{4}$ & $\begin{array}{l}35 \% \\
\left(\mathrm{H}_{2} \mathrm{O}_{2}\right)+10 \% \\
\left(\mathrm{FeSO}_{4}\right)\end{array}$ & $50{ }^{\circ} \mathrm{C}$ & $24 \mathrm{~h}$ & $\begin{array}{l}\mathrm{NaOH} \\
(0.5 \mathrm{M}, \\
24 \mathrm{~h}) \\
\text { soni, } \\
\text { centri }\end{array}$ & Sie & $\begin{array}{l}1,0.25 \\
0.05 \mathrm{~mm}\end{array}$ & $\begin{array}{l}\mathrm{H}_{2} \mathrm{O}_{2}, \mathrm{D} \\
\left(80^{\circ} \mathrm{C}\right)\end{array}$ & $\begin{array}{l}\text { Zhang and Liu } \\
\text { (2018) }\end{array}$ \\
\hline DS, OD & $\begin{array}{l}\mathrm{D} \\
\left(65^{\circ} \mathrm{C}\right), \\
\text { sie }\end{array}$ & $\mathrm{NaCl}$ & 1.2 & Centri & - & - & $\mathrm{HNO}_{3}$ & $65 \%$ & $90{ }^{\circ} \mathrm{C}$ & $48 \mathrm{~h}$ & $\begin{array}{l}\mathrm{NaCl} \\
\text { rinse }\end{array}$ & Mem & $0.2 \mu \mathrm{m}$ & - & $\begin{array}{l}\text { Scheurer and } \\
\text { Bigalke (2018) }\end{array}$ \\
\hline DS & Sie & $\mathrm{NaCl}$ & 1.2 & - & - & - & - & - & - & - & - & - & - & - & $\begin{array}{l}\text { Álvarez-Hernández } \\
\text { et al. (2019) }\end{array}$ \\
\hline PFE & - & - & - & - & - & - & - & - & - & - & - & - & - & - & $\begin{array}{l}\text { Fuller and Gautam } \\
(2016)\end{array}$ \\
\hline DS & - & Dw & - & $\begin{array}{l}\text { Man, } \\
\text { Ultra }\end{array}$ & $\begin{array}{l}\text { Over } \\
\text { night }\end{array}$ & - & $\begin{array}{l}\text { Fenton's } \\
\text { reagent }\end{array}$ & - & - & - & - & - & $<3 \mu \mathrm{m}$ & $\begin{array}{l}\mathrm{D} \\
\left(60{ }^{\circ} \mathrm{C}\right), \\
\text { Heated } \\
130{ }^{\circ} \mathrm{C}\end{array}$ & $\begin{array}{l}\text { S. Zhang et al. } \\
(2020)\end{array}$ \\
\hline DS & $\mathrm{AD}$, sie & Dw & - & $\begin{array}{l}\text { Man, } \\
\text { Ultra }\end{array}$ & $\begin{array}{l}\text { Over } \\
\text { night }\end{array}$ & - & - & - & - & - & - & - & $<3 \mu \mathrm{m}$ & $\begin{array}{l}\mathrm{D} \\
\left(60{ }^{\circ} \mathrm{C}\right), \\
\text { Heated } \\
130{ }^{\circ} \mathrm{C}\end{array}$ & $\begin{array}{l}\text { S. Zhang et al. } \\
\text { (2018) }\end{array}$ \\
\hline
\end{tabular}

a OD (organic digestion), DS (density separation), SI ( sieving), PFE (pressurized fluid extraction).

b Centri (centrifugation), D (drying), AD (air-drying), sie (sieving).

c Dw (distilled water).

d Ultra (ultrasonification), man (manual stirring).

e Soni (sonification).

\subsection{Polymer identification}

Following MP extraction, polymer identification techniques are conducted to allow researchers to adjust their visual counting results to true MP quantities by discarding false positives. Many techniques have been developed and applied for this matter; including Fourier transform infrared spectroscopy (FTIR) and its configurations, Raman spectroscopy, pyrolysis coupled to gas chromatography and mass spectrometry (Pyr-GC/MS) and scanning electron microscopy (SEM) coupled to energy dispersive X-ray spectroscopy (SEM-EDS) as the main polymer identification methods. Some studies have investigated unconventional techniques as potential alternatives, including vis-NIR spectroradiometry applications (Corradini et al., 2019), pressurized liquid extraction or thermal desorption coupled to GC/MS (Dierkes et al., 2019; Dümichen et al., 2017), although reporting critical limitations for realistic applications.

FTIR is widely used in literature to analyze MPs sampled from many environmental matrices. Polymer identification is carried out by automatically comparing the FTIR spectrum from a MP to reference spectra (Fig. 2), the polymer spectrum with the highest similarity is suggested as the chemical identity of the analyzed particle. Establishing a similarity threshold (e.g., $\geq 70 \%, \geq 80 \%$ ) with the spectrum of highest percentage of similarity is a common practice to determine a grade of certainty when reporting polymer identities. Extra peaks in the FTIR spectra and low similarity percentage may be due to adhered contaminants and weathering conditions resulting in polymer degradation (De-la-Torre et al., 2020). Brandon et al. (2016) investigated how different weathering conditions alter chemical bond structure in microplastics. Results indicated evident bond changes in the FTIR spectra, mainly in the hydroxyl $\left(3350 \mathrm{~cm}^{-1}\right)$, carboxyl groups $\left(1640 \mathrm{~cm}^{-1}\right)$ and carbon-oxygen bonds $\left(1070 \mathrm{~cm}^{-1}\right)$. Bond index for these groups varied depending on the polymer, time of exposure and weathering conditions (Brandon et al., 2016). Furthermore, soil characteristics (e.g. temperature, oxygen levels, moisture, composition) are part of the main factors that promote plastic degradation ( $\mathrm{Ng}$ et al., 2018). This process may cause bond changes in the FTIR spectra by altering the molecular structure of the particles. Therefore, in order to improve the certainty of polymer identification, an automated comparison with a spectral library may be accompanied with a manual spectral analysis following the description of environmentally weathered plastics by Jung et al. (2018) and bond changes described by Brandon et al. (2016). Soil organic matter can also reduce the effectiveness of FTIR analysis (Li et al., 2020a, 2020b). To avoid interference with surface organic matter and impurities, a smooth clean surface of the MP can be exposed by making a small cut (Jung et al., 2018). For the smaller samples, a preliminary cleaning treatment with $1 \mathrm{M} \mathrm{HCl}$ and $30 \%$ hydrogen peroxide $\left(\mathrm{H}_{2} \mathrm{O}_{2}\right)$ for 2 or 3 min can be applied (Mecozzi et al., 2016). Other drawbacks 


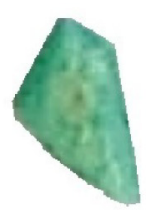

PP

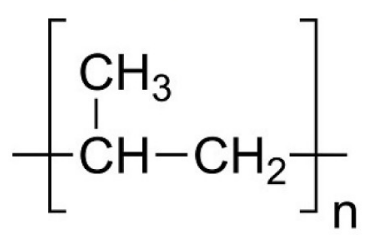

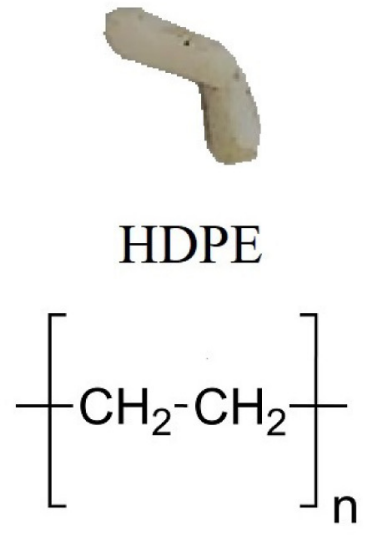

\section{Sample spectrum}

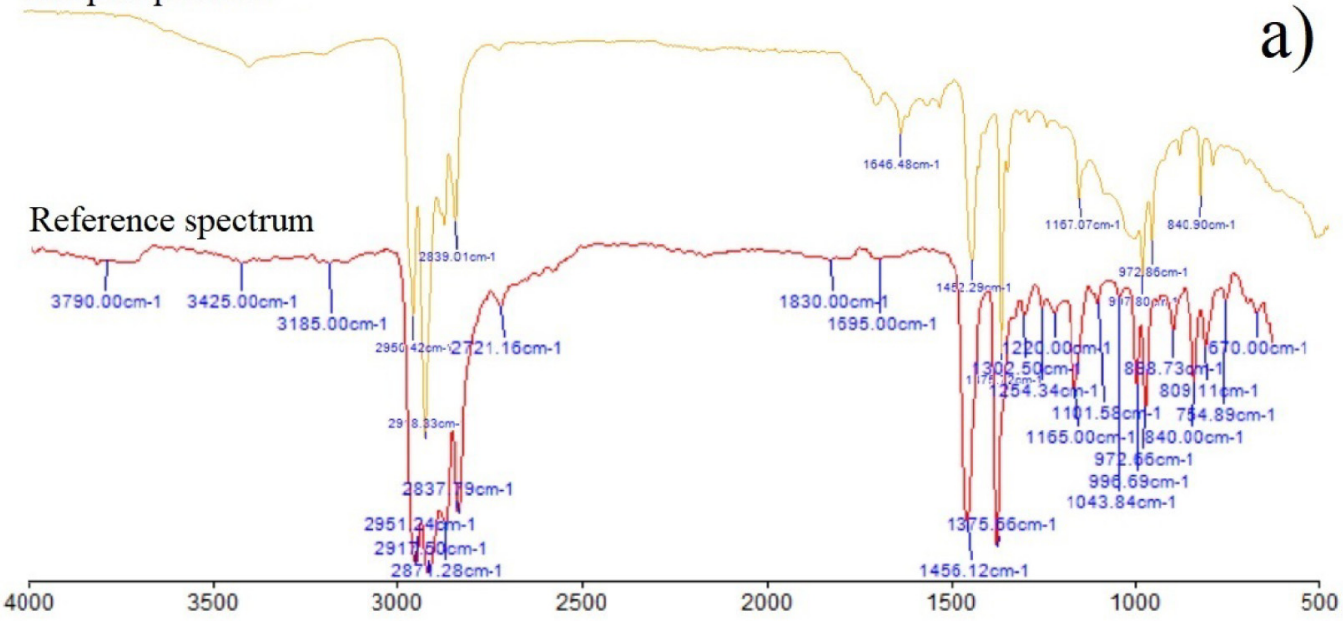

Sample spectrum

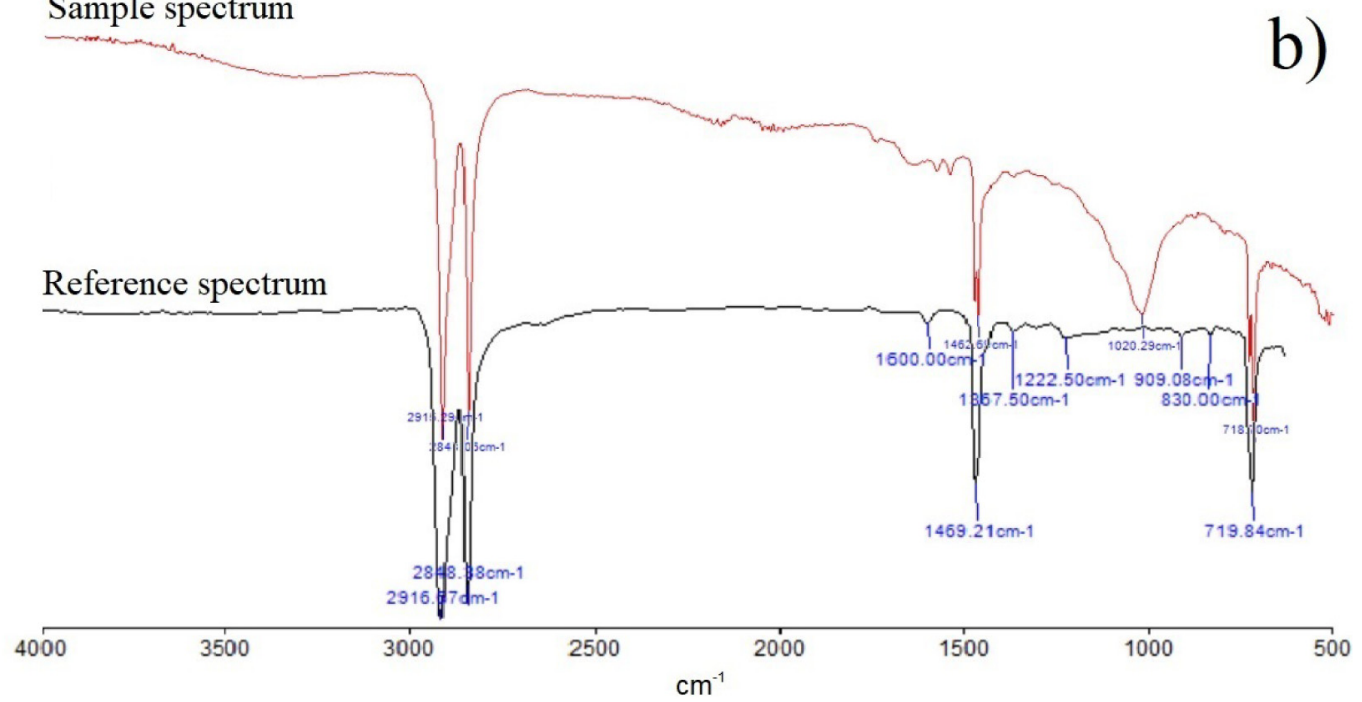

Fig. 2. Reference and sample FTIR spectra of previously identified MP polymers. a) Polypropylene FTIR spectra. b) High density polyethylene FTIR spectra.

that must to be taken into account are moisture interference with the reading and the impossibility to identify black particles, small fibers, and tiny particles as a technical challenge, requiring extensive practical experience (Käppler et al., 2016). Moisture interference can be avoided if the samples and filters are oven dried before the FTIR analysis. When coupled to a microscope ( $\mu$ FTIR), microplastics as small as $10 \mu \mathrm{m}$ are analyzed, while a focal plane array (FPA) allows to obtain both chemical and morphological information simultaneously (Wang et al., 2020), overcoming size limit drawbacks and fasten the procedure by directly scanning over the filtered samples (Simon et al., 2018)

In spite of Raman spectroscopy not being as common as FTIR in literature, it is beneficial to overcome some FTIR technical limitations.

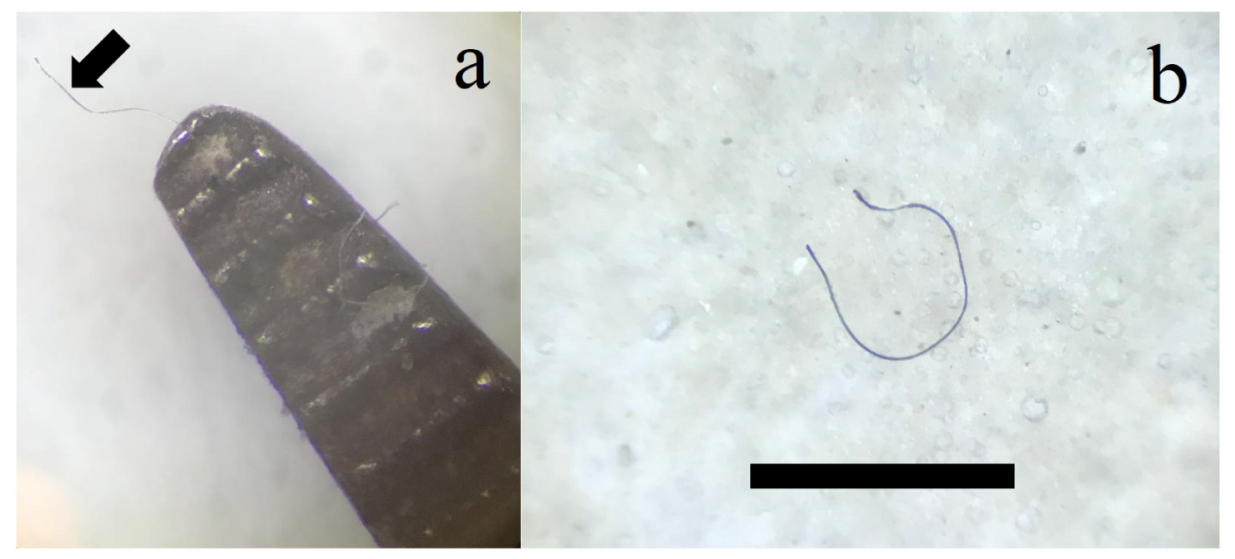

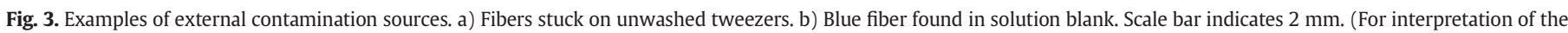
references to color in this figure legend, the reader is referred to the web version of this article.) 
Particles even smaller than $1 \mu \mathrm{m}$ are detected by Raman spectroscopy when coupled to a microscope, although certain technical skill is generally required; it also exhibits better spectral resolution and lower moisture signal interference than FTIR (Ribeiro-Claro et al., 2017). Regarding its drawbacks, the high-energy intensity of its laser could destroy MP particles (Dehaut et al., 2019) and plastic additives could obstruct the Raman spectra of synthetic polymers (Karami et al., 2018; Van Cauwenberghe and Janssen, 2014). The additives causing major modification to the spectra are mostly fillers, pigments and dyes (Lenz et al., 2015).

Pyr-GC/MS is a destructive method used to obtain structural information of the MPs chemical composition by analyzing the products of thermal degradation (Fries et al., 2013). Pre-treatment is not required, and small sample quantities (5-20 $\mu \mathrm{g}$ ) are needed (Kusch, 2017). Compared to spectroscopic techniques, sequential Pyr-GC/MS is able to analyze plastic additives (Qiu et al., 2016). SEM provides a highmagnification image of MPs, aiming for a structural false positive discrimination. When coupled with energy-dispersive spectroscopy (SEM-EDS), determination of the elemental composition is enabled (Blair et al., 2019). The lack of strong C signal in elemental spectra suggests a non-synthetic particle. However, SEM-EDS may be subject to laborious, expensive and time-consuming procedures, limiting the number of analyzed particles (Silva et al., 2018). These methods may have been overlooked, as they are not commonly used in literature.

Some of the methods described before were used in studies researching the presence of MP in terrestrial ecosystems (Table 2). Out of the 12 retrieved articles, seven used FTIR configurations ( $\mu$ FTIR and ATR-FTIR), and two used Raman spectroscopy configurations ( $\mu$ Raman). Three articles did not employ synthetic polymer validation and were limited to visual identification. The accepted similarity percentage threshold varied from $\geq 50 \%$ to $80 \%$. Threshold percentages as low as $50 \%$ may fall into wrong polymer identification. Ideally, $100 \%$ of the MPs must be analyzed in order to have a full comprehension of polymer type occurrence and completely identify MPs. Only Y. Zhou et al. (2019) analyzed the entirety of the MP extracted from soil, while the majority only analyzed a portion of the isolated MPs. The MPs selected for polymer identification must be representative of the morphological types and colors, as carried out by B. Zhou et al. (2019). Analytical parameters, like the minimum percentage of total MPs to be analyzed and similarity threshold vary considerably among studies and require standardization.

\subsection{Contamination prevention}

The ubiquitous presence and low concentrations of MPs in the samples makes post-sampling contamination a threat to the reliability of the results (Dehaut et al., 2019), which must be taken in serious regard as it can bias the quantification of MPs and further interpretation of their effects (Hermsen et al., 2017; Nel and Froneman, 2015; Woodall et al., 2015) (See Fig. 3). Therefore, rigorous and standardized quality assurance and quality control measures must be applied during the whole experimental process in order to improve the quality of the results and facilitate comparison with other studies (Wang and Wang, 2018; Zarfl, 2019).

Among the studies consulted, 83\% (10 of 12) of them indicated an implementation of quality assurance or quality control measures (QA) QC). That may look as a good percentage, nonetheless to make a further assessment of the QA/QC measurements applied in literature, we took into account the parameters established by Dehaut et al. (2019): contamination from the operator, contamination from the work environment, contamination from used solutions and controls of contaminations. The results are presented on Table 3.

With respect to the contamination prevention from the operator, the use of inappropriate clothing can significantly bias the results of the experiments as clothing can release plastic fibers into the samples depending on the level of friction due to the activity being conducted (Scopetani et al., 2020). Following this, 58\% of the studies mentioned the use of special clothes. Lab coats and gloves were used on $50 \%$ and $20 \%$ of the studies respectively. The majority of the coats used were made from cotton. Only one study used non-textile caps to prevent contamination with human hair. No further indications or details of the cleaning and storage of the laboratory clothing were given, even though they can also be contaminated during the cleaning process on washing machines (Dehaut et al., 2019) or due to airborne MP particles.

As a complementary practice to reduce the risk of contamination by the operator, a "sticky roller" can be used to clean the lab coats (Bråte et al., 2016). Dehaut et al. (2019) also suggested the usage of protection boxes to store the gloves and a cleaning procedure for them using filtered water/alcohol solutions or compressed air. Compressed air can also be applied to clean the lab coats, and coat cases can be used to prevent contamination of airborne MP particles. Woodall et al. (2015) suggest the usage of boiler suits and keeping laboratory clothes in laboratory environments. It is recommended to use polymer identification techniques as cotton clothes may release more fibers than clothes made of synthetic fibers (Scopetani et al., 2020).

Regarding contamination from the work environment, there are two aspects to take into account: the facility where the study is being carried out and the materials and equipment used (Dehaut et al., 2019). The ubiquitous presence of MPs increases the importance of special locations to avoid contamination from airborne particles. Only two studies (17\%) mentioned the use of a special location, a fume hood and a laboratory deemed for MPs only. Apart from using a fume hood, Zhang and

Table 3

Summary of the contamination prevention measures used in the selected studies.

\begin{tabular}{|c|c|c|c|c|c|c|c|c|}
\hline $\mathrm{QA} / \mathrm{QC}$ & Filtering & $\begin{array}{l}\text { Special lab } \\
\text { clothe }^{a}\end{array}$ & $\begin{array}{l}\text { Work } \\
\text { place }\end{array}$ & Blank $^{\mathrm{b}}$ & $\begin{array}{l}\text { Blank } \\
\text { management }{ }^{\mathrm{c}}\end{array}$ & Cleaning \& rising $^{\mathrm{d}}$ & $\begin{array}{l}\text { Sample } \\
\text { cover }\end{array}$ & Reference \\
\hline Yes & Yes & - & - & Sol, Pc & Subtraction & $\mathrm{Uw} / \mathrm{HCl}(20 \% v / v)$ rised with $\mathrm{Uw}$ & - & Y. Zhou et al. (2019) \\
\hline Yes & - & Coat $^{\mathrm{c}}$ & - & Con, Sol, Pc & Averaged & - & Yes & Corradini et al. (2019) \\
\hline Yes & - & Coat $^{\mathrm{c}}$ & - & Pro & $\mathrm{NF}$ & Filtered de-ionized water and 35\% ethanol & Yes & Piehl et al. (2018) \\
\hline Yes & - & Coat $^{\mathrm{c}} /$ gloves $^{\mathrm{c}}$ & - & Pro, Pc & $\mathrm{NF}$ & Mqw & - & Liu et al. (2018) \\
\hline Yes & Yes & - & - & $\mathrm{Ab}, \mathrm{Cs}$ & Average $^{\mathrm{n}}$ & Uw & - & Chen et al. (2019) \\
\hline Yes & - & Coat $^{\text {nt }} /$ gloves $^{\text {nt }}$ & - & Pro & Subtraction & Mqw & - & B. Zhou et al. (2019) \\
\hline Yes & - & Coat & Fumehood & $\mathrm{Ab}$ & Average $^{\mathrm{n}}$ & Yes & Yes & Zhang and Liu (2018) \\
\hline Yes & - & - & - & Pro, Pc & Average $^{\mathrm{n}}$ & - & - & Scheurer and Bigalke (2018) \\
\hline No & - & - & - & - & - & - & - & $\begin{array}{l}\text { Álvarez-Hernández et al. } \\
\text { (2019) }\end{array}$ \\
\hline No & - & - & - & - & - & - & - & Fuller and Gautam (2016) \\
\hline Yes & - & Yes* & - & - & - & - & - & S. Zhang et al. (2020) \\
\hline Yes & - & Yes* & - & Pc & - & - & Yes & S. Zhang et al. (2018) \\
\hline
\end{tabular}

${ }^{a} \mathrm{c}$ (Cotton), ${ }^{\mathrm{nt}}$ (no textile), *(clothes made from plastic fibers were not allowed).

b Sol (solution), Pc (positive control), Con (container), Pro (procedural), Ab (airborne), Cs (cleaning solution).

${ }^{\text {c }} \mathrm{NF}$ (no MPs found), ${ }^{\text {n }}$ (negligible concentrations on blank).

${ }^{\mathrm{d}}$ Uw (ultrapure water), Mqw (miliQ water). 
Liu (2018) also covered their samples with aluminum foil. Other three studies covered their samples as well with aluminum foil, glassware or petri dishes, being a total of $33 \%$ of the studies that covered their samples when not in use.

The reduction of air circulation, the filtration of air on the workplace and further analysis of the filters, and the use of clean bench setup have been suggested by authors to reduce contamination from airborne MPs particles (Wang and Wang, 2018; Wesch et al., 2017; Zarfl, 2019). The results of Wesch et al. (2017) indicated that a clean bench is a better option than the fume hood to reduce MPs contamination.

Most studies limited the use of plastic labware and tools and when not possible, controls were implemented. With respect to cleaning and rising procedures, $42 \%$ of the studies mentioned the implementation of such. Ultrapure or MilliQ water were used in $50 \%$ of the studies to clean equipment, tools, containers and instruments.

Regarding contamination from reagents, only $17 \%$ of the studies filtered their solutions using $0.45 \mu \mathrm{m}$ membranes in both cases. The filtration of the solutions used in MP studies is strongly recommended to remove particles that may contaminate the samples (Dehaut et al., 2019; Bergmann et al., 2017; Woodall et al., 2015).

At last, with respect to the use of blanks or controls, almost all studies that implemented QA/QC measurements used at least one type of blank. Nevertheless, the quantity and type of blanks used varied among studies. $33 \%$ of the studies used more than one type of blank during the experiment. Procedural blanks and positive controls were used by $33 \%$ of the studies each. Solvent/solute blanks and airborne blanks were used by $17 \%$ of the studies each. Concerning the results of the blanks, $17 \%$ of the studies normalized their results by subtracting the MPs found in the blanks for every sample batch with the ones of their blanks, 33\% just presented the average results of the blanks and 17\% did not find MPs on their blanks. Importantly, three of the four studies reporting the average MP concentration in the blanks found negligible concentrations on them.

There are no fixed measurements for QA/QC purposes for MP experiments in general (Hanvey et al., 2017; Wesch et al., 2017; Zarfl, 2019). Even though the majority of the studies consulted presented some mention of $\mathrm{QA} / \mathrm{QC}$ measurements, these focus mainly on the use of blanks and cotton coats, leaving aside important measurements identified by other authors (e.g., filtering of the solutions used, use of clean bench, covering the samples when they are not in use, air circulation restriction). Implementation of a unique standard or protocol for contamination prevention on MP experiments is of great importance, as it will allow the comparison among studies and achieve accurate results (Hanvey et al., 2017; He et al., 2018). Further investigation of the best techniques to reduce the risk of sample contamination has to be done in order to complement traditional methods, as they have been proven not to be sufficient to reduce contamination of the sample (Wesch et al., 2017).

\subsection{Novel method alternatives}

Fifteen studies presenting novel analytical methods applied to soil samples were retrieved. Among the studies consulted, promising techniques for MP extraction alternatives and standardization were presented, along with straightforward techniques, like hyperspectral imaging, vis-NIR spectroradiometry, and techniques associated to thermal degradation. Here, we reviewed and discussed the alternative methods available in literature.

Several authors developed new promising methodologies for the isolation of MPs in soils. Liu et al. (2019) created a circulation system that includes a floating solution of sodium bromide ( $\mathrm{NaBr}$ ) for a highspeed density separation after $\mathrm{H}_{2} \mathrm{O}_{2}$ digestion. This process proved to be highly efficient and significantly reduces reagent waste. However, Hurley et al. (2018) noted that performing the oxidation process of $\mathrm{H}_{2} \mathrm{O}_{2}$ after density separation is inefficient, as many MPs trapped in organic matter are lost, as well as showing difficult visual identification.
Han et al. (2019) improved the floating solution by proposing a saturated mixture of $99.5 \%$ calcium chloride $\left(\mathrm{CaCl}_{2}\right)$ and $99 \% \mathrm{NaI}$, followed by a 40 -s aeration step and vacuum filtration of the supernatant. Results showed that the average recovery of different polymer types ranged from 78 to $100 \%$. In order to remove organic material, digestion with $30 \% \mathrm{H}_{2} \mathrm{O}_{2}$ has been applied in various studies ( $\mathrm{Li}$ et al., 2019; Liu et al., 2019). In spite of this, Hurley et al. (2018) observed that $\mathrm{H}_{2} \mathrm{O}_{2}$ at $70{ }^{\circ} \mathrm{C}$ may degrade the mass $(-26.7 \%)$ and size $(-33.4 \%)$ of the polymer PA-6.6. Moreover, the application of the Fenton reagent as described by Hurley et al. (2018) generates an exothermic reaction, potentially damaging MPs. Mani et al. (2019) developed a method using castor oil as an alternative for a safe, environmentally friendly, fast and costefficient MP isolation. According to Mani et al. (2019), soil samples were placed in a separatory funnel, $100 \mathrm{ml}$ of distilled water was added, and were shaken by hand for $30 \mathrm{~s}$. Then $10 \mathrm{ml}$ of castor oil was added and allowed to stand for $15 \mathrm{~min}$. The irrelevant part of the matrix was significantly reduced ( $95 \pm 4 \%$ ), along with highly efficient polymer recovery. Importantly, S. Zhang et al. (2018) indicated that a 3-5 s heating at $130{ }^{\circ} \mathrm{C}$ may facilitate the identification of low-density MPs. In general, the studies consulted agreed that high-density solutions are the best alternative in achieving the highest MP recovery from soil samples during floatation. Some alternatives were suggested, among soluble salt mixtures, reagents and oil. For light density MP polymers, distilled water may be sufficient (S. Zhang et al., 2018). Some high-density solutions like NaI may also promote the floatation of impurities depending on the sample characteristics, thus multiple repetitions may be required to overcome this. The selection of the isolating substance must consider cost-efficiency, handling, MP recovery rates and possible damage or loss of certain polymers in order to avoid biased results.

Shan et al. (2018) investigated hyperspectral imaging technology, image processing and chemometric techniques for the detection of MP in situ The results showed that the support vector machine (SVM) was the most applicable method to detect white and black PE in the soil, with accuracies ranging from 58 to $84 \%$ depending on size and color, while being able to distinguish plastic particles from other organic objects. However, this technology is limited to MPs ranging from 0.5 to $5 \mathrm{~mm}$ in size. Hence, this method may be appropriate for a first baseline assessment on surface MP contamination.

Two of the consulted papers applied vis-NIR spectroradiometry technology to assess MP in soil samples. Corradini et al. (2019) used a portable spectroradiometer that works near the visible-infrared range (vis-NIR) to rapidly assess MP concentrations in soils, although only was able to identify MPs at critical points of contamination. Likewise, $\mathrm{Ng}$ et al. (2019) tested the same vis-NIR spectroradiometry method, but in order to predict the presence of MPs in the soil matrix, a convolutional neural network ( $\mathrm{CNN}$ ) model was proposed as a regression model for soil properties predictor using spectral data. This method was, however, unable to classify PET and LDPE MPs accurately.

David et al. (2018) and Yu et al. (2019) used thermogravimetrymass spectrometry (TGA-MS) techniques to quantify the MPs. Yu et al. (2019) coupled a FTIR to the system for MP identification. The samples were pyrolyzed by TGA and the gases were identified by FTIR, adding security to the results as temperature profiles, and absorption spectra differ between several common plastics. Dierkes et al. (2019) developed a method that combines extraction with pressurized liquid extraction (PLE) coupled to GC-MS pyrolysis for the quantification of MPs. MP (PE, PP and PS) recovery reached $>80 \%$ of efficiency in soil and sediments matrices. The analysis revealed high statistical uncertainties due to the non-homogeneous distribution of MPs, as seen in other studies (e.g., Dümichen et al., 2017; Ng et al., 2019). It was recommended to completely homogenize soil samples for accurate results. Dümichen et al. (2017) and Watteau et al. (2018) developed a thermo-analytic method as the first step for the identification of MPs. In the method proposed by Dümichen et al. (2017), soil samples are subject to a complete thermal degradation. The polymer samples are identified by means of 
Table 4

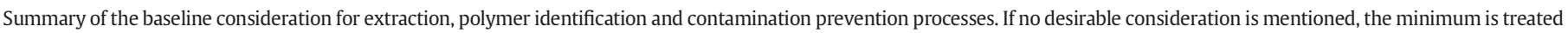
as mandatory.

\begin{tabular}{|c|c|c|c|c|c|}
\hline Process & & Element & Minimum & Desirable & Avoid \\
\hline \multirow[t]{4}{*}{ Extraction } & \multirow[t]{2}{*}{ Organic digestion } & Reagent & $\mathrm{KOH}, \mathrm{H}_{2} \mathrm{O}_{2}$ & - & $\mathrm{HNO}_{3}, \mathrm{NaOH}$ \\
\hline & & Temperature & $<80^{\circ} \mathrm{C}$ & $60{ }^{\circ} \mathrm{C}$ & $>80{ }^{\circ} \mathrm{C}$ \\
\hline & Density separation & Reagent & $\mathrm{NaCl}$ & $\mathrm{NaI}, \mathrm{CaCl}_{2}$ & - \\
\hline & Filtration & Pore size & $\leq 20 \mu \mathrm{m}$ & $\leq 8 \mu \mathrm{m}$ & $>20 \mu \mathrm{m}$ \\
\hline \multirow[t]{2}{*}{ Polymer identification } & \multirow[t]{2}{*}{ Spectroscopy } & Percentage similarity threshold & $>75 \%$ & - & $\leq 75 \%$ \\
\hline & & \# of particles analyzed & $10 \%^{\mathrm{a}}$ & $100 \%$ & - \\
\hline \multirow{8}{*}{$\begin{array}{l}\text { Contamination } \\
\text { prevention }\end{array}$} & \multirow[t]{2}{*}{ Prior sample treatment } & Filtration & All liquids ${ }^{\mathrm{b}}$ & - & - \\
\hline & & Cleaning reagent & Pre-filtered water & Distilled/Ultrapure water & Tap water \\
\hline & \multirow[t]{6}{*}{ During process } & Materials and tools & Glass, metal & - & Plastic \\
\hline & & Sample and liquids & Cover when not in used & - & - \\
\hline & & Work environment & Clean surfaces, reduced air flow & Fume hood/laminar flow cabinet & - \\
\hline & & Clothing & Latex gloves, cotton lab coat & $100 \%$ cotton clothing, nitrile gloves & Synthetic clothes \\
\hline & & Blank & Procedural, airborne & - & - \\
\hline & & Blank results treatment & Report, normalization $^{c}$ & - & - \\
\hline
\end{tabular}

\footnotetext{
a The selected sub-sample must be representative of all MP types while giving priority to the smallest MPs.

b Pore size must be smaller than the one used for sample treatment.

c Subtracting MPs in blanks from raw data matching type and color.
}

thermal desorption GC coupled to MS. Thermal-analytical methods pose a promising alternative for a fast MP identification and quantification straight from soil samples, although many frontiers and challenges are still to overcome in order to come out with a fast, integrative and costefficient method.

\section{Knowledge gaps and recommendations}

Only $25 \%$ of the studies specified the taxonomy of the soil where the samples were taken and only one specified the texture. The importance of this remains on the efficiency of the extraction and identification methodologies as presented above. Moreover, soil characteristics can help to explain the results of environmental assessments. For example, it has been experimentally demonstrated that soil texture has a direct influence on MP transportation (Li et al., 2020a, 2020b), along with other soil characteristics, such as organic matter content, ionic strength and water saturation (Xu et al., 2019). Thus, reporting the soil texture, taxonomy and physicochemical properties is necessary. We suggest applying the USDA textural classification system as it is the most widely used (Yolcubal et al., 2004) and most suited for agricultural soils. Regarding soil taxonomy, the US soil taxonomy classification system as in Piehl et al. (2018), Zhang and Liu (2018) and S. Zhang et al. (2020) is recommended.

Few studies evaluated the presence of MP on different soil layers, most of them having a sampling depth between 0 and $30 \mathrm{~cm}$ (Xu et al., 2019). The necessity to evaluate MP transport and distribution among soil profiles considering shapes and sizes have been addressed by Zhang and Liu (2018) and Corradini et al. (2019). Possible affectation of the shallow groundwater has also been suggested by Piehl et al. (2018), making this subject of major concern.

The current knowledge is not enough to portray a worldwide overview of MP abundance and distribution. Site-specific MP sources are key to prevent and monitor MP pollution. However, there is still significant uncertainty regarding occurrence, distribution and fate of MPs in the soil ecosystem around the globe. The lack of standardized protocols was pointed out as one major frontier. Thus, a set of baseline considerations (Table 4 ) based on current literature and previous research was described.

\section{Conclusion}

MPs are a ubiquitous contaminant in terrestrial ecosystems potentially causing ill effects on soil biota and altering soil properties. Here, we made a comprehensive summary of the abundance, main sources and distribution of MPs in terrestrial ecosystems. The current available literature regarding the presence of MPs in terrestrial ecosystems is very limited. Thus, requiring further substantial and comprehensive research at a global scale. The MP assessment process, including MPs isolation and identification, were described in detail. The whole process must be accompanied by contamination prevention measures in order to assure the accuracy of the results. As no standard protocol has been established, the methodology applied differs significantly among studies. Thus, results are not compatible and difficult to compare. Hence, we established minimal and desirable conditions for the entire process and considerations for different MP parameters (morphological and chemical characteristics). The knowledge gaps identified are regarding the influence of the soil type on the extraction efficiency, vertical distribution and fate of MPs.

\section{Declaration of competing interest}

The authors declare that they have no known competing financial interests or personal relationships that could have appeared to influence the work reported in this paper.

\section{Acknowledgements}

The authors are thankful to the five anonymous peer reviewers for their constructive comments and suggestions. This research was partially supported by Universidad San Ignacio de Loyola.

\section{References}

Álvarez-Hernández, C., Cairós, C., López-Darias, J., Mazzetti, E., Hernández-Sánchez, C., González-Sálamo, J., Hernández-Borges, J., 2019. Microplastic debris in beaches of Tenerife (Canary Islands, Spain). Mar. Pollut. Bull. 146, 26-32. https://doi.org/10.1016/j. marpolbul.2019.05.064.

Alvarez-Zeferino, J.C., Ojeda-Benítez, S., Cruz-Salas, A.A., Martínez-Salvador, C., VázquezMorillas, A., 2020. Microplastics in Mexican beaches. Resour. Conserv. Recy. 155, 104633. https://doi.org/10.1016/j.resconrec.2019.104633.

Andrady, A.L., 2011. Microplastics in the marine environment. Mar. Pollut. Bull. 62, 1596-1605. https://doi.org/10.1016/j.marpolbul.2011.05.030.

Barboza, L.G.A., Gimenez, B.C.G., 2015. Microplastics in the marine environment: current trends and future perspectives. Mar. Pollut. Bull. 97, 5-12. https://doi.org/10.1016/j. marpolbul.2015.06.008.

Bergmann, M., Wirzberger, V., Krumpen, T., Lorenz, C., Primpke, S., Tekman, M.B., Gerdts, G., 2017. High quantities of microplastic in arctic deep-sea sediments from the Hausgarten observatory. Environ. Sci. Technol. 51, 11000-11010. https://doi.org/ 10.1021/acs.est.7b03331.

Blair, R.M., Waldron, S., Phoenix, V.R., 2019. Microscopy and elemental analysis characterisation of microplastics in sediment of a freshwater urban river in Scotland, UK. Environ. Sci. Poll. Res. 26, 12491-12504. https://doi.org/10.1007/s11356-019-04678-1.

Bordós, G., Urbányi, B., Micsinai, A., Kriszt, B., Palotai, Z., Szabó, I., Hantosi, Z., Szoboszlay, S., 2019. Identification of microplastics in fish ponds and natural freshwater environments of the Carpathian basin, Europe. Chemosphere 216, 110-116. https://doi.org/ 10.1016/j.chemosphere.2018.10.110.

Bosker, T., Bouwman, L.J., Brun, N.R., Behrens, P., Vijver, M.G., 2019. Microplastics accumulate on pores in seed capsule and delay germination and root growth of the terrestrial 
vascular plant Lepidium sativum. Chemosphere 226, 774-781. https://doi.org/ 10.1016/j.chemosphere.2019.03.163.

Brandon, J., Goldstein, M., Ohman, M.D., 2016. Long-term aging and degradation of microplastic particles: comparing in situ oceanic and experimental weathering patterns. Mar. Pollut. Bull. 110, 299-308. https://doi.org/10.1016/j. marpolbul.2016.06.048.

Bråte, I.L.N., Eidsvoll, D.P., Steindal, C.C., Thomas, K.V., 2016. Plastic ingestion by Atlantic cod (Gadus morhua) from the Norwegian coast. Mar. Pollut. Bull. 122, 105-110. https://doi.org/10.1016/j.marpolbul.2016.08.034.

Browne, M.A., Galloway, T., Thompson, R., 2009. Microplastic-an emerging contaminant of potential concern? Integr. Environ. Assess. Manag. 3, 559-561. https://doi.org/ 10.1002/ieam.5630030412.

Camacho, M., Herrera, A., Gómez, M., Acosta-Dacal, A., Martínez, I., Henríquez-Hernández, L.A., Luzardo, O.P., 2019. Organic pollutants in marine plastic debris from Canary Islands beaches. Sci. Total Environ. 662, 22-31. https://doi.org/10.1016/j. scitotenv.2018.12.422.

Chen, Y., Leng, Y., Liu, X., Wang, J., 2019. Microplastic pollution in vegetable farmlands of suburb Wuhan, central China. Environ. Pollut. 257, 113449. https://doi.org/10.1016/j. envpol.2019.113449.

Chen, Y., Liu, X., Leng, Y., Wang, J., 2020. Defense responses in earthworms (Eisenia fetida) exposed to low-density polyethylene microplastics in soils. Ecotoxicol. Environ. Saf. 187, 109788. https://doi.org/10.1016/j.ecoenv.2019.109788.

Cole, M., Lindeque, P., Halsband, C., Galloway, T.S., 2011. Microplastics as contaminants in the marine environment: a review. Mar. Pollut. Bull. 62, 2588-2597. https://doi.org/ 10.1016/j.marpolbul.2011.09.025.

Conley, K., Clum, A., Deepe, J., Lane, H., Beckingham, B., 2019. Wastewater treatment plants as a source of microplastics to an urban estuary: removal efficiencies and loading per capita over one year. Water Res. X 3, 100030. https://doi.org/10.1016/j. wroa.2019.100030.

Corradini, F., Meza, P., Eguiluz, R., Casado, F., Huerta-Lwanga, E., Geissen, V., 2019. Evidence of microplastic accumulation in agricultural soils from sewage sludge disposal. Sci. Total Environ. 671, 411-420. https://doi.org/10.1016/j.scitotenv.2019.03.368.

David, J., Steinmetz, Z., Kučerík, J., Schaumann, G.E., 2018. Quantitative analysis of poly (ethylene terephthalate) microplastics in soil via thermogravimetry-mass spectrometry. Anal. Chem. 90, 8793-8799. https://doi.org/10.1021/acs.analchem.8b00355.

Dehaut, A., Hermabessiere, L., Duflos, G., 2019. Current frontiers and recommendations for the study of microplastics in seafood. TrAC-Trend. Anal. Chem. 116, 346-359. https://doi.org/10.1016/j.trac.2018.11.011.

De-la-Torre, G.E., 2020. Microplastics: an emerging threat to food security and human health. J. Food Sci. Technol. 57, 1601-1608. https://doi.org/10.1007/s13197-01904138-1.

De-la-Torre, G.E., Dioses-Salinas, D.C., Castro, J.M., Antay, R., Fernández, N.Y., EspinozaMorriberón, D., Saldaña-Serrano, M., 2020. Abundance and distribution of microplastics on sandy beaches of Lima, Peru. Mar. Pollut. Bull. 151, 110877. https://doi.org/10.1016/j.marpolbul.2019.110877.

Desforges, J.-P.W., Galbraith, M., Dangerfield, N., Ross, P.S., 2014. Widespread distribution of microplastics in subsurface seawater in the NE Pacific Ocean. Mar. Pollut. Bull. 79, 94-99. https://doi.org/10.1016/j.marpolbul.2013.12.035.

Desforges, J.-P.W., Galbraith, M., Dangerfield, N., Ross, P.S., 2015. Ingestion of microplastics by zooplankton in the Northeast Pacific Ocean. Arch. Environ. Con. Tox. 69, 320-330. https://doi.org/10.1007/s00244-015-0172-5.

Dierkes, G., Lauschke, T., Becher, S., Schumacher, H., Földi, C., Ternes, T., 2019. Quantification of microplastics in environmental samples via pressurized liquid extraction and pyrolysis-gas chromatography. Anal. Bioanal. Chem. 411, 6959-6968. https://doi.org/ 10.1007/s00216-019-02066-9.

Dümichen, E., Eisentraut, P., Bannick, C.G., Barthel, A.-K., Senz, R., Braun, U., 2017. Fast identification of microplastics in complex environmental samples by a thermal degradation method. Chemosphere 174, 572-584. https://doi.org/10.1016/j. chemosphere.2017.02.010.

Fries, E., Dekiff, J.H., Willmeyer, J., Nuelle, M.-T., Ebert, M., Remy, D., 2013. Identification of polymer types and additives in marine microplastic particles using pyrolysis-GC/MS and scanning electron microscopy. Environ. Sci.: Process. Impacts 15, 1949-1956. https://doi.org/10.1039/C3EM00214D.

Fuller, S., Gautam, A., 2016. A procedure for measuring microplastics using pressurized fluid extraction. Environ. Sci. Technol. 50, 5774-5780. https://doi.org/10.1021/acs. est.6b00816

Galgani, F., Hanke, G., Werner, S., Oosterbaan, L., Nilsson, P., Fleet, D., Kinsey, S., Thompson, R.C., van Franeker, J., Vlachogianni, T., Scoullos, M., Veiga, J.M., Palatinus, A., Matiddi, M., Maes, T., Korpinen, S., Budziak, A., Leslie, H., Gago, J., Liebezeit, G., 2013. Guidance on Monitoring of Marine Litter in European Seas. Publications Office of the European Union, Luxembourg.

Garcia, T.M., Campos, C.C., Mota, E.M.T., Santos, N.M.O., Campelo, R.P. de S., Prado, L.C.G., Junior, M.M., Soares, M. de O., 2020. Microplastics in subsurface waters of the western equatorial Atlantic (Brazil). Mar. Pollut. Bull. 150, 110705. https://doi.org/10.1016/j. marpolbul.2019.110705.

Han, X., Lu, X., Vogt, R.D., 2019. An optimized density-based approach for extracting microplastics from soil and sediment samples. Environ. Pollut. 254, 113009. https:// doi.org/10.1016/j.envpol.2019.113009.

Hanvey, J.S., Lewis, P.J., Lavers, J.L., Crosbie, N.D., Pozo, K., Clare, B.O., 2017. A review of analytical techniques for quantifying microplastics in sediments. Anal. Methods 9, 1369. https://doi.org/10.1039/c6ay02707e.

He, D., Luo, Y., Lu, S., Liu, M., Song, Y., Lei, L., 2018. Microplastics in soils: analytical methods, pollution characteristics and ecological risks. Trend. Anal. Chem. 109, 163-172. https://doi.org/10.1016/j.trac.2018.10.006.
Hermsen, E.., Pompe, R., Besseling, E., Koelmans, A.A., 2017. Detection of low numbers of microplastics in North Sea fish using strict quality assurance criteria. Mar. Pollut. Bull. 122, 253-258. https://doi.org/10.1016/j.marpolbul.2017.06.051.

Huang, Y., Liu, Q., Jia, W., Yan, C., Wang, J., 2020. Agricultural plastic mulching as a source of microplastics in the terrestrial environment. Environ. Pollut. 260, 114096. https:// doi.org/10.1016/j.envpol.2020.114096.

Huerta Lwanga, E., Gertsen, H., Gooren, H., Peters, P., Salánki, T., van der Ploeg, M., Besseling, E., Koelmans, A.A., Geissen, V., 2016. Microplastics in the terrestrial ecosystem: implications for Lumbricus terrestris (Oligochaeta, Lumbricidae). Environ. Sci. Technol. 50, 2685-2691. https://doi.org/10.1021/acs.est.5b05478.

Huerta Lwanga, E., Gertsen, H., Gooren, H., Peters, P., Salánki, T., van der Ploeg, M., Besseling. E., Koelmans, A.A., Geissen, V., 2017. Incorporation of microplastics from litter into burrows of Lumbricus terrestris. Environ. Pollut. 220, 523-531. https:// doi.org/10.1016/j.envpol.2016.09.096.

Hurley, R.R., Lusher, A.L., Olsen, M., Nizzetto, L., 2018. Validation of a method for extracting microplastics from complex, organic-rich, environmental matrices. Environ. Sci. Technol. 52, 7409-7417. https://doi.org/10.1021/acs.est.8b01517.

Jung, M.R., Horgen, F.D., Orski, S.V., Rodriguez C., V., Beers, K.L., Balazs, G.H., Todd Jones, T., Work, T.M., Brignac, K.C., Royer, S.J., Hyrenbach, K.D., Jensen, B.A., Lynch, J.M. 2018. Validation of ATR FT-IR to identify polymers of plastic marine debris, including those ingested by marine organisms. Mar. Pollut. Bull. 127, 704-716. doi:https:// doi.org/10.1016/j.marpolbul.2017.12.061.

Käppler, A., Fischer, D., Oberbeckmann, S., Schernewski, G., Labrenz, M., 2016. Analysis of environmental microplastics by vibrational microspectroscopy: FTIR, Raman or both? Anal. Bioanal. Chem. 408, 8377-8391. https://doi.org/10.1007/s00216-016-9956-3.

Karami, A., Golieskardi, A., Choo, C.K., Larat, V., Karbalaei, S., Salamatinia, B., 2018. Microplastic and mesoplastic contamination in canned sardines and sprats. Sci. Total Environ. 612, 1380-1386. https://doi.org/10.1016/j.scitotenv.2017.09.005.

Kusch, P., 2017. Chapter 7 - application of pyrolysis-gas chromatography/mass spectrometry (Py-GC/MS). Comp. Anal. Chem. 75, 169-207. https://doi.org/10.1016/bs. coac.2016.10.003.

Lei, L., Liu, M., Song, Y., Lu, S., Hu, J., Cao, C., Xie, B., Shi, H., He, D., 2018. Polystyrene (nano) microplastics cause size-dependent neurotoxicity, oxidative damage and other adverse effects in Caenorhabditis elegans. Environ. Sci. Nano 5, 2009-2020. https:// doi.org/10.1039/C8EN00412A.

Lenz, R., Enders, K., Stedmon, C.A., Mackenzie, D.M.A., Nielsen, T.G., 2015. A critical assessment of visual identification of marine microplastic using Raman spectroscopy for analysis improvement. Mar. Pollut. Bull. 100, 82-91. https://doi.org/10.1016/j. marpolbul.2015.09.026.

Li, Q., Wu, J., Zhao, X., Gu, X., Ji, R., 2019. Separation and identification of microplastics from soil and sewage sludge. Environ. Pollut. 254, 113076. https://doi.org/10.1016/ j.envpol.2019.113076.

Li, W., Lo, H.-S., Wong, H.-M., Zhou, M., Wong, C.-Y., Tam, N.F.-Y., Cheung, S.-G., 2020a. Heavy metals contamination of sedimentary microplastics in Hong Kong. Mar. Pollut. Bull. 153, 110977. https://doi.org/10.1016/j.marpolbul.2020.110977.

Li, J., Song, Y., Cai, Y., 2020b. Focus topics on microplastics in soil: analytical methods, occurrence, transport, and ecological risks. Environ. Pollut. 257, 113570. https://doi.org 10.1016/j.envpol.2019.113570.

Lima, A.R.A., Barletta, M., Costa, M.F., 2015. Seasonal distribution and interactions between plankton and microplastics in a tropical estuary. Estuar. Coast. Shelf Sci. 165, 213-225. https://doi.org/10.1016/j.ecss.2015.05.018.

Liu, M., Lu, S., Song, Y., Lei, L., Hu, J., Lv, W., Zhou, W., Cao, C., Shi, H., Yang, X., He, D., 2018. Microplastic and mesoplastic pollution in farmland soils in suburbs of Shanghai, China. Environ. Pollut. 242, 855-862. https://doi.org/10.1016/j.envpol.2018.07.051.

Liu, M., Song, Y., Lu, S., Qiu, R., Hu, J., Li, X., Bigalke, M., Shi, H., He, D., 2019. A method for extracting soil microplastics through circulation of sodium bromide solutions. Sci. Total Environ. 691, 341-347. https://doi.org/10.1016/j.scitotenv.2019.07.144.

Mani, T., Frehland, S., Kalberer, A., Burkhardt-Holm, P., 2019. Using castor oil to separate microplastics from four different environmental matrices. Anal. Methods 11, 1788-1794. https://doi.org/10.1039/C8AY02559B.

Md Amin, R., Sohaimi, E.S., Anuar, S.T., Bachok, Z., 2020. Microplastic ingestion by zooplankton in Terengganu coastal waters, southern South China Sea. Mar. Pollut. Bull. 150, 110616. https://doi.org/10.1016/j.marpolbul.2019.110616.

Mecozzi, M., Pietroletti, M., Monakhova, Y.B., 2016. FTIR spectroscopy supported by statistical techniques for the structural characterization of plastic debris in the marine environment: application to monitoring studies. Mar. Pollut. Bull. 106, 155-161. https:// doi.org/10.1016/j.marpolbul.2016.03.012.

Nel, H.A., Froneman, P.W., 2015. A quantitative analysis of microplastic pollution along the south-eastern coastline of South Africa. Mar. Pollut. Bull. 101, 274-279. https:// doi.org/10.1016/j.marpolbul.2015.09.043.

Ng, E.L., Huerta Lwanga, E., Eldridge, S.M., Johnston, P. Hu, H.W. Geissen, V., Chen, D. 2018. An overview of microplastic and nanoplastic pollution in agroecosystems. Sci. Total Environ. 627, 1377-1388. https://doi.org/10.1016/j.scitotenv.2018.01.341.

Ng, W., Minasny, B., McBratney, A., 2019. Convolutional neural network for soil microplastic contamination screening using infrared spectroscopy. Sci. Total Environ. 702, 134723. https://doi.org/10.1016/j.scitotenv.2019.134723.

Ory, N.C., Sobral, P., Ferreira, J.L., Thiel, M., 2017. Amberstripe scad Decapterus muroadsi (Carangidae) fish ingest blue microplastics resembling their copepod prey along the coast of Rapa Nui (Easter Island) in the South Pacific subtropical gyre. Sci. Total Environ. 586, 430-437. https://doi.org/10.1016/j.scitotenv.2017.01.175.

Piehl, S., Leibner, A., Löder, M.G.J., Dris, R., Bogner, C., Laforsch, C., 2018. Identification and quantification of macro- and microplastics on an agricultural farmland. Sci. Rep. 8 , 17950. https://doi.org/10.1038/s41598-018-36172-y.

Qi, Y., Yang, X., Pelaez, A.M., Lwanga, E.H., Beriot, N., Gertsen, H., Garbeva, P., Geisen, V., 2018. Macro- and micro- plastics in soil-plant system: effects of plastic mulch film 
residues on wheat (Triticum aestivum) growth. Sci. Total Environ. 645, 1048-1056. https://doi.org/10.1016/j.scitotenv.2018.07.229.

Qi, R., Jones, D.L., Li, Z., Liu, Q., Yan, C., 2020. Behavior of microplastics and plastic film residues in the soil environment: a critical review. Sci. Total Environ. 703, 134722. https://doi.org/10.1016/j.scitotenv.2019.134722.

Qiu, Q., Tan, Z., Wang, J., Peng, J., Li, M., Zhan, Z., 2016. Extraction, enumeration and identification methods for monitoring microplastics in the environment. Estuar. Coast. Shelf Sci. 176, 102-109. https://doi.org/10.1016/j.ecss.2016.04.012.

Ribeiro-Claro, P., Nolasco, M.M., Araújo, C., 2017. Chapter 5-characterization of microplastics by Raman spectroscopy. Compr. Anal. Chem. 75, 119-151. https://doi. org/10.1016/bs.coac.2016.10.001.

Scheurer, M., Bigalke, M., 2018. Microplastics in Swiss floodplain soils. Environ. Sci. Technol. 52, 3591-3598. https://doi.org/10.1021/acs.est.7b06003.

Scopetani, C., Esterhuizen-Londt, M., Chelazzi, D., Cincicnelli, A., Setälä, H., Pflugmacher, S., 2020. Self-contamination from clothing in microplastics research. Ecotoxicol. and Environ. Saf. 189, 110036. https://doi.org/10.1016/j.ecoenv.2019.110036.

Shan, J., Zhao, J., Liu, L., Zhang, Y., Wang, X., Wu, F., 2018. A novel way to rapidly monitor microplastics in soil by hyperspectral imaging technology and chemometrics. Environ. Pollut. 238, 121-129. https://doi.org/10.1021/acs.est.7b06003.

Shang, X., Lu, J., Feng, C., Ying, Y., He, Y., Fang, S., Lin, Y., Dahlgren, R., Ju, J., 2020. Microplastic ( 1 and $5 \mu \mathrm{m}$ ) exposure disturbs lifespan and intestine function in the nematode Caenorhabditis elegans. Sci. Total Environ. 705, 135837. https://doi.org/ 10.1016/j.scitotenv.2019.135837.

Shim, W.J., Hong, S.H., Eo, S., 2018. Abundance, distribution, and composition. In: Zeng, E.Y. (Ed.), Microplastic Contamination in Aquatic Environments. Elsevier, Amsterdam, pp. 1-26.

Silva, A.B., Bastos, A.S., Justino, C.I.L., da Costa, J.P., Duarte, A.C., Rocha-Santos, T.A.P., 2018. Microplastics in the environment: challenges in analytical chemistry - a review. Anal. Chim. 1017, 1-19. https://doi.org/10.1016/j.aca.2018.02.043.

Silva-Cavalcanti, J.S., Silva, J.D.B., de França, E.J., de Araújo, M.C.B., Gusmão, F., 2017. Microplastics ingestion by a common tropical freshwater fishing resource. Environ. Pollut. 221, 218-226. https://doi.org/10.1016/j.envpol.2016.11.068.

Simon, M., van Alst, N., Vollertsen, J., 2018. Quantification of microplastic mass and removal rates at wastewater treatment plants applying Focal Plane Array (FPA)based Fourier Transform Infrared (FT-IR) imaging. Water Res. 142, 1-9. https://doi. org/10.1016/j.watres.2018.05.019.

Sommer, F., Dietze, V., Baum, A., Sauer, J., Gilge, S., Maschowski, C., Gieré, R., 2018. Tire abrasion as a major source of microplastics in the environment. Aerosol Air Qual. Res. 18, 2014-2018. https://doi.org/10.4209/aaqr.2018.03.0099.

de Souza Machado, A.A., Lau, C.W., Till, J., Kloas, W., Lehmann, A., Becker, R., Rilling, C. 2018. Impacts of microplastics on the soil biophysical environment. Environ. Sci. Technol. 52, 9656-9665. https://doi.org/10.1021/acs.est.8b02212.

Sun, X, Li, Q Shi, Y, Zhao, Y. Zheng S. Liang J. Liu, T., Tian, Z, 2019. Characteristics and retention of microplastics in the digestive tracts of fish from the Yellow Sea. Environ. Pollut. 249, 878-885. https://doi.org/10.1016/j.envpol.2019.01.110.

Talvitie, J., Mikola, A., Koistinen, A., Setälä, O., 2017. Solutions to microplastic pollution removal of microplastics from wastewater effluent with advanced wastewater treatment technologies. Water Res. 123, 401-407. https://doi.org/10.1016/j. watres.2017.07.005.

Van Cauwenberghe, L., Janssen, C.R., 2014. Microplastic in bivalves cultured for human consumption. Environ. Pollut. 193, 65-70. https://doi.org/10.1016/j. envpol.2014.06.010.

Van Cauwenberghe, L., Devriese, L., Galgani, F., Robbens, J., Janssen, C.R., 2015. Microplastics in sediments: a review of techniques, occurrence and effects. Mar. Environ. Res. 111, 5-17. https://doi.org/10.1016/j.marenvres.2015.06.007.

Van den Berg, P., Huerta-Lwanga, E., Corradini, F., Violette, G., 2020. Sewage sludge application as a vehicle for microplastics in eastern Spanish agricultural soils. Environ. Pollut. 261, 114198. https://doi.org/10.1016/j.envpol.2020.114198.

Wang, W., Wang, J., 2018. Investigation of microplastics in aquatic environments: an overview of the methods used, from field sampling to laboratory analysis. Trends in Anal. Chem. 108, 195-202. https://doi.org/10.1016/j.trac.2018.08.026.

Wang, J., Liu, X., Li, Y., Powell, T., Wang, X., Wang, G., Zhang, P., 2019. Microplastics as contaminants in the soil environment: a mini-review. Sci. Total Environ. 691, 848-857. https://doi.org/10.1016/j.scitotenv.2019.07.209.
Wang, W., Ge, J., Yu, X., Li, H., 2020. Environmental fate and impacts of microplastics in soil ecosystems: Progress and perspective. Sci. Total Environ. 708, 134841. https:// doi.org/10.1016/j.scitotenv.2019.134841.

Watteau, F., Dignac, M.-F., Bouchard, A., Revallier, A., Houot, S., 2018. Microplastic detection in soil amended with municipal solid waste composts as revealed by transmission electronic microscopy and pyrolysis/GC/MS. Front. Sustain.Food Sys. 2, 81. https://doi.org/10.3389/fsufs.2018.00081.

Weithmann, N., Möller, J.N., Löder, M.G.J., Piehl, S., Laforsch, C., Freitag, R., 2018. Organic fertilizer as a vehicle for the entry of microplastic into the environment. Sci. Adv. 4, eaap8060. https://doi.org/10.1126/sciadv.aap8060.

Wesch, C., Elert, A.M., Wörner, M., Braun, U., Klein, R., Paulus, M., 2017. Assuring quality in microplastic monitoring: about the value of clean-air devices as essentials for verified data. Sci. Rep. 7, 5424. https://doi.org/10.1038/s41598-017-05838-4.

Wong, G., Löwemark, L., Kunz, A., 2020. Microplastic pollution of the Tamsui River and its tributaries in northern Taiwan: spatial heterogeneity and correlation with precipitation. Environ. Pollut. 260, 113935. https://doi.org/10.1016/j.envpol.2020.113935.

Woodall, L.C., Gwinnett, C., Packer, M., Thompson, R.C., Robinson, L.F., Paterson, G.L.J., 2015. Using Forensic Science Approach to Minimize Environmental Contamination and to Identify Microfibres in Marine Sediments. vol. 95, 40-46. http://dx.doi.org/ https://doi.org/10.1016/j.marpolbul.2015.04.044.

Wu, C., Zhang, K., Xiong, X., 2017. Microplastic pollution in inland waters focusing on Asia. In: Wagner, M., Lambert, S. (Eds.), Freshwater Microplastics. The Handbook of Environmental Chemistry, 1st edn 58. Springer, Cham, pp. 85-99 vol.

Wu, Q., Tao, H., Wong, M.H., 2018. Feeding and metabolism effects of three common microplastics on Tenebrio molitor L. Environ. Geochem. Health 41, 17-26. https:// doi.org/10.1007/s10653-018-0161-5.

Xu, B., Liu, F., Cryder, Z., Huang, D., Lu, Z., He, Y., Wang, H., Lu, Z., Brookes, P.C., Tang, C., Gan, J., Xu, J., 2019. Microplastics in the soil environment: occurrence, risks, interactions and fate - a review. Crit. Rev. in Environ. Sci. Technol. https://doi.org/10.1080/ 10643389.2019.1694822.

Yolcubal, I., Brusseau, M.L., Artiola, J.F., Wierenga, P., Wilson, L.G., 2004. Environmental physical properties and processes. In: Artiola, J.F., Pepper, I.L., Brusseau, M.L. (Eds.), Environmental Monitoring and Characterization. Academic Press, pp. 207-239. https://doi.org/10.1016/B978-012064477-3/50014-X.

Yu, J., Wang, P., Ni, F., Cizdziel, J., Wu, D., Zhao, Q., Zhou, Y., 2019. Characterization of microplastics in environment by thermal gravimetric analysis coupled with Fourier transform infrared spectroscopy. Mar. Pollut. Bull. 145, 153-160. https://doi.org/ 10.1016/j.marpolbul.2019.05.037.

Zarfl, C., 2019. Promising techniques and open challenges for microplastic identification and quantification in environmental matrices. Anal. Bioanal. Chem. 411, 3743-3756. https://doi.org/10.1007/s00216-019-01763-9.

Zhang, G.S., Liu, Y.F., 2018. The distribution of microplastics in soil aggregate fractions in southwestern China. Sci. Total Environ. 642, 12-20. https://doi.org/10.1016/j. scitotenv.2018.06.004

Zhang, S., Yang, X., Gertsen, H., Peters, P., Salánki, T., Geissen, V., 2018. A simple method for the extraction and identification of light density microplastics from soil. Sci. Total Environ. 616-617, 1056-1065. https://doi.org/10.1016/j.scitotenv.2017.10.213.

Zhang, S., Liu, X., Hao, X., Wang, J., Zhang, Y., 2020a. Distribution of low-density microplastics in the mollisol farmlands of northeast China. Sci. Total Environ. 708, 135091. https://doi.org/10.1016/j.scitotenv.2019.135091.

Zhang, B., Yang, X., Chen, L., Chao, J., Teng, J., Wang, Q., 2020b. Microplastics in soil: a review of possible sources, analytical methods and ecological impacts. J. Chem. Technol. Biotechnol. https://doi.org/10.1002/jctb.6334.

Zhou, Y., Liu, X., Wang, J., 2019a. Characterization of microplastics and the association of heavy metals with microplastics in suburban soil of central China. Sci. Total Environ. 694, 133798. https://doi.org/10.1016/j.scitotenv.2019.133798.

Zhou, B., Wang, J., Zhang, H., Shi, H., Fei, Y., Huang, S., Tong, Y., Wen, D., Luo, Y., Barceló, D. 2019b. Microplastics in agricultural soils on the coastal plain of Hangzhou Bay, east China: multiple sources other than plastic mulching film. J. Hazard. Mater. https:// doi.org/10.1016/j.jhazmat.2019.121814 